Discussion Paper No. 12-075

\title{
How Relevant is Job Mismatch for German Graduates?
}

Francesco Berlingieri and Daniel Erdsiek

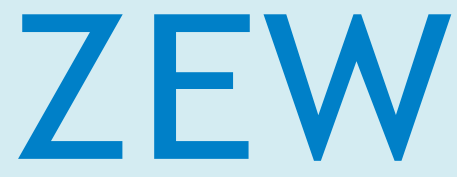

Zentrum für Europäische Wirtschaftsforschung $\mathrm{GmbH}$

Centre for European Economic Research 
Discussion Paper No. 12-075

\title{
How Relevant is Job Mismatch for German Graduates?
}

\author{
Francesco Berlingieri and Daniel Erdsiek
}

Download this ZEW Discussion Paper from our ftp server:

http://ftp.zew.de/pub/zew-docs/dp/dp12075.pdf

Die Discussion Papers dienen einer möglichst schnellen Verbreitung von neueren Forschungsarbeiten des ZEW. Die Beiträge liegen in alleiniger Verantwortung der Autoren und stellen nicht notwendigerweise die Meinung des ZEW dar.

Discussion Papers are intended to make results of ZEW research promptly available to other economists in order to encourage discussion and suggestions for revisions. The authors are solely responsible for the contents which do not necessarily represent the opinion of the ZEW. 


\section{Non-technical summary}

The mismatch between workers' supply of skills and demand for skills in the labour market is at the forefront of the policy debate in European countries. On the one hand, the education sector is heavily subsidised in Germany and other European countries. Particularly, tertiary education expanded in the last decade with an increase in public investment. In the context of strong public budget constraints, this gives rise to concerns of a possible overinvestment in education resulting in an oversupply of skills. On the other hand, firms claim that they increasingly face difficulties in filling their vacancies because of a lack of sufficiently qualified labour force. The effectiveness of higher education in producing adequately skilled graduates thus represents a concern for many economic actors.

In this study, we provide a conceptual underpinning of the possible explanations of job-worker mismatch and its implication for different actors in the economy. We define mismatch distinguishing between the perspective of the employee, the employer and the overall economy. From the overall economy and the employer perspective, optimality of a job match hinges on productivity, while what matters for employees is the utility associated to a job. The empirical literature generally employs two kinds of concepts for identifying job-worker mismatches. Qualification mismatch occurs if the level of formal education a worker possesses deviates from the one required for the job; skill mismatch occurs if the worker possesses a higher or lower level of skills than required to perform the job. This study provides an overview of measures and empirical findings concerning these concepts.

Focusing on German graduates, we examine the incidence and direct consequences of job mismatch employing measures from three different datasets. The rate of overqualification and skill mismatch is found to differ strongly between fields of study, type of university and gender. Information about job requirements and the worker's level in jobrelevant competences are employed to infer skill surpluses and deficits among graduates in more detail.

Additionally, we investigate to what extent jobs of overqualified or skill mismatched graduates are different from jobs held by matched graduates. The results indicate that jobs of matched graduates exhibit higher complexity and creativity requirements while being less monotone than jobs of mismatched graduates. The highest differences in these job characteristics are found if matched graduates are compared to graduates being overqualified and skill mismatched simultaneously. For causal analyses, i.e. regarding wage effects of job mismatch, self-selection is a severe problem. Using direct survey information on reasons for accepting a particular job and satisfaction with job characteristics, this study provides results pointing towards possible self-selection of graduates into job mismatch. 


\section{Das Wichtigste in Kürze}

Ein Mismatch zwischen dem Angebot an Fähigkeiten durch die Erwerbsbevölkerung und der Nachfrage nach Fähigkeiten am Arbeitsmarkt steht im Fokus der politischen Diskussion in europäischen Ländern. Auf der einen Seite wird Bildung, insbesondere auch tertiäre Bildung, in Deutschland und anderen europäischen Ländern stark subventioniert. Angesichts staatlicher Budgetbeschränkungen stellt sich dabei die Frage, ob durch hohe Investitionen in das Bildungswesen ein Überangebot an hochqualifizierten Arbeitnehmern verursacht wird. Auf der anderen Seite beklagen Unternehmen, dass es zunehmend schwieriger wird, ausreichend qualifizierte Arbeitnehmer zu finden um vakante Stellen zu besetzen. Mit welcher Effizienz der tertiäre Bildungssektor adäquat qualifizierte Absolventen für den Arbeitsmarkt hervorbringt, ist demnach für verschiedene Wirtschaftsakteure von Bedeutung.

In der vorliegenden Studie werden für den Mismatch zwischen Beschäftigung und Arbeitnehmer mögliche Erklärungen und Implikationen aus konzeptioneller Sicht untersucht. Wichtig ist hierbei, relevante Perspektiven bei der Definition von Mismatch zu berücksichtigen. Aus Arbeitgebersicht und gesamtwirtschaftlicher Perspektive hängt es von der Produktivität ab, ob die Passung zwischen Arbeitnehmer und Beschäftigung optimal ist. Dagegen ist für Arbeitnehmer der Nutzen entscheidend, der mit der Tätigkeit verbunden ist. In der empirischen Literatur werden in der Regel zwei Konzepte verwendet, um einen Mismatch zu identifizieren. Ein „Qualification Mismatch” liegt vor, wenn eine Beschäftigung nicht den formalen Bildungsabschluss erfordert, den ein Arbeitnehmer erworben hat. Besitzt ein Arbeitnehmer ein anderes Niveau an Fähigkeiten als es seine Beschäftigung erfordert, liegt ein „Skill Mismatch” vor. Diese Studie bietet einen Überblick über Maße und empirische Ergebnisse bezüglich dieser zwei Konzepte.

Im empirischen Teil der Studie untersuchen wir anhand von drei Datensätzen, wie häufig deutsche Hochschulabsolventen von Mismatch betroffen sind und welche direkten Konsequenzen damit verbunden sind. Das Aufkommen von Mismatch variiert stark in Abhängigkeit von Studienfach, Art der Hochschule und Geschlecht. Um für Absolventen Überschüsse und Defizite in berufsrelevanten Kompetenzen genauer zu erfassen, vergleichen wir spezifische Berufsanforderungen mit den Fähigkeiten von Absolventen.

Zusätzlich untersuchen wir, inwiefern Unterschiede zwischen adäquater und inadäquater Beschäftigung bestehen. Die Ergebnisse deuten darauf hin, dass adäquat beschäftigte Absolventen Berufe ausüben, die ein höheres Maß an Komplexität und Kreativität aufweisen und gleichzeitig weniger monotone Tätigkeiten umfassen als Berufe von inadäquat beschäftigten Absolventen. Für Absolventen, die gleichzeitig von Qualification Mismatch und Skill Mismatch betroffen sind, sind diese Unterschiede besonders ausgeprägt. Für Kausalanalysen, z.B. zu Lohneffekten von Mismatch, stellt Selbstselektion in eine inadäquate Beschäftigung ein schwerwiegendes Problem dar. Anhand von Informationen über die Gründe eine Beschäftigung zu wählen und der Zufriedenheit mit Berufscharakteristika liefert diese Studie Hinweise für eine mögliche Selbstselektion von Absolventen. 


\title{
How Relevant is Job Mismatch for German Graduates?*
}

\author{
Francesco Berlingieri ${ }^{\dagger}$ \\ Daniel Erdsiek ${ }^{\S}$
}

November 2012

\begin{abstract}
In this study, we examine the incidence and direct consequences of job mismatch for German graduates. Beyond measuring job mismatch by the comparison of qualification obtained by employees and required for a job, we employ self-reported skill mismatch variables concerning overall skills and more detailed information about the surplus or deficit in specific competences. The results indicate that a substantial share of graduates underutilizes own skills in the job. The rate of overqualification and skill mismatch is found to differ strongly between fields of study, type of university and gender. In addition, we investigate to what extent jobs of matched graduates differ from jobs held by mismatched graduates. Jobs of the latter are found to exhibit lower complexity and creativity requirements but to be more monotone than matching jobs. Furthermore, we provide a conceptual underpinning of the possible explanations of job-worker mismatch and its implication for different actors in the economy.
\end{abstract}

JEL-classification: J24, I2

Keywords: job mismatch, overqualification, skill mismatch

*This paper was written as part of the project "Adequate employment of graduates: An economical analysis of job match quality" (ADÄQUAT) supported within the programme "Economics of Science" by the German Ministry of Education and Research (BMBF, research grant 01PW11019). We thank Nora Grote for competent research assistance and Melanie Arntz, Marianne Saam and Maresa Sprietsma for helpful comments and discussions. The views expressed in this article are those of the authors and do not necessarily reflect the views of the BMBF. All opinions and mistakes are our own.

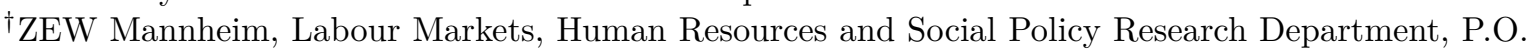
Box 103443, D-68034 Mannheim, email: berlingieri@zew.de.

§ZEW Mannheim, ICT Research Group, P.O. Box 103443, D-68034 Mannheim, email: erdsiek@zew.de. 


\section{Introduction}

The mismatch between workers' supply of skills and demand for skills in the labour market is at the forefront of the policy debate in European countries (Cedefop, 2010). On the one hand, the education sector is heavily subsidised in Germany and other European countries. Particularly, tertiary education has expanded in the last decade with an increase in public investment (OECD, 2012). ${ }^{1}$ In the context of strong public budget constraints related to the ageing populations and the recent debt crises, this gives rise to concerns of a possible overinvestment in education resulting in an oversupply of skills. On the other hand, firms claim that they increasingly face difficulties in filling their vacancies because of a lack of sufficiently qualified labour force. ${ }^{2}$ The effectiveness of higher education in producing adequately skilled graduates thus represents a concern for many economic actors.

While changes in relative wages might theoretically indicate whether mismatches are present in the economy, wages are not fully flexible in European countries because of different labour market institutions. Therefore, direct measures of job mismatch can help to better understand the relevance of mismatches between the human capital provided by workers and the needs of the economy, as well as the causes of such mismatches. In this paper, we aim to identify appropriate measures of job mismatch and to clarify the relevance of job mismatch for German graduates by field of study, type of university and gender. Moreover, we identify research questions that are relevant and feasible for future research based on a review of the available data for Germany and the existing empirical literature.

In the past decades, there has been extensive research on job mismatch on the individual level. While the main focus has been on overqualification, namely if a worker holds a higher level of qualification than typically required by the job, several studies have recently also employed self-reported measures of skill mismatch, such as underutilization of overall skills in the job (Allen and van der Velden, 2001; Quintini, 2011). However, in a recent overview of this literature, Leuven and Oosterbeek (2011) point out, among other things, that the conceptualization of overeducation and job mismatch has not been properly addressed. We attempt to tackle the issue from a broader perspective and in a first step provide a conceptual analysis on the possible causes and explanations of job-worker mismatch based on contributions not only from economics, but also from psychology and human resource management. To underline that mismatch might be perceived differently by distinct economic actors, we define job mismatch distinguishing between the perspective of the employer, the employee and the overall economy. In a second step, we provide an overview of the literature on educational and skill mismatch highlighting the main empirical findings on the incidence and causes of mismatch for different economic sectors

\footnotetext{
${ }^{1}$ In Germany, for example, public expenditures for tertiary education increased of about $20 \%$ between 2007 and 2011 (Destatis, 2011).

${ }^{2}$ See for example: http://www.universityworldnews.com/article.php?story= 20110325204522328.
} 
and socio-demographic characteristics.

Previous literature on the job match of German graduates has focused almost exclusively on overqualification (Plicht et al., 1994; Bauer, 2002; Büchel, 2002). We contribute to this literature by additionally employing self-reported measures on mismatch in overall skills and specific competences. Previous studies have mainly concentrated on indirect consequences of job mismatch by analysing effects on wages or the overall job satisfaction. We employ more direct consequences of job mismatches to show how German graduates are affected by overqualification and skill mismatch.

First, we analyse how qualification and skill mismatch correlate to the match between competences possessed by the worker and required by the job. Using information about a set of 19 specific competences, we show that qualification and skill mismatch come along with a surplus of different job-relevant competences, such as analytical thinking or mastery of own field. Second, detailed information about job requirements is used to analyse how jobs of overqualified and skill mismatched graduates differ from jobs of matched graduates. We find that mismatched employees hold jobs which are less complex and creative but more monotone. With respect to demanding job characteristics, we find a stronger negative correlation for overqualification than for skill mismatch. The least demanding jobs as measured by level of complexity, creativity and monotony are held by graduates who are simultaneously overqualified and skill mismatched. Third, we analyse graduates' satisfaction with respect to a set of 15 job characteristics and find a strong correlation with overqualification for most items.

Employees' satisfaction with job characteristics could also contain some information about self-selection into overqualification. Since self-selection into overqualification or skill mismatch can cause severe endogeneity problems for causal analysis of productivity effects of job mismatch, we take a first step to approach this issue. We find that wellmatched graduates are more satisfied with most of the surveyed job characteristics, i.e. job content, professional position or earnings. However, overqualified graduates are more satisfied than matched graduates with respect to space for private life and scope/length of working time. More direct information about job choice is provided by employing a question concerning the reasons for taking the current job. Overqualified graduates more often indicate that a lack of job alternatives or the avoidance of unemployment were important reasons for taking their current job. Furthermore, the proximity to native place and family-related reasons seem to play a role for the selection into overqualification. In contrast, the firm reputation and interesting tasks were more crucial for matched graduates than for overqualified graduates.

The paper is organized in the following way. Definitions of mismatch from the perspectives of the employer, the employee and the overall economy are provided in Section 2. Section 3 gives an overview of the empirical evidence on job mismatch. We summarize how the existing literature operationalizes the concepts of job-worker mismatch highlighting potential problems and identifying relevant unanswered questions. Section 4 
introduces four relevant German datasets highlighting information contained that is relevant for research on job mismatch. Furthermore, it presents selected descriptive results, and it concludes with the identification of open research questions to be possibly tackled in future research.

\section{Definition of Job Mismatch}

Job mismatch is the object of a vast amount of theoretical and empirical literature not only in economics, but also in psychology and sociology. Nevertheless, there is hardly any paper that carries out a conceptual analysis of job-worker mismatch taking into account the contributions of these different strands of literature. ${ }^{3}$ In this section, we provide a conceptual underpinning of the possible explanations of job-worker mismatch and its implication for different actors in the economy. Following Sattinger (2012), we define job mismatch distinguishing between the perspective of the overall economy, the employer and the employee. From the overall economy and the employer perspective, optimality of a job match hinges on productivity, while what matters for employees is the utility associated to a job. Even if there is an obvious relationship between these three definitions, highlighting the possible differences helps to understand the different implications of the mismatch measures employed. The definitions of job mismatch rely on the existence of a set of heterogeneous workers and a set of heterogeneous jobs at a given point in time. Moreover, we consider the match outcome to be determined by the interaction of the worker's characteristics and the job requirements.

\subsection{Overall Economy Perspective}

We define a worker-job match to be optimal from an overall economy perspective if either the same worker cannot be paired with another job or a given job cannot be filled with another worker into a more productive match (Pellizzari, 2011). If such mismatches occur, the available human capital in the economy is not used efficiently implying productivity losses. In a country with high subsidies for education, this can also lead to lower public returns for education caused by lower revenues through income taxes. In a neoclassical setting with no frictions, perfect information and perfect foresight, no suboptimal match takes place in equilibrium. Relaxing the perfect foresight assumption, imbalances could arise because of an unexpected shift in labour demand or supply. Labour demand shifts, which could be unexpected at the time of the individual educational investment, could occur through rapid changes in job skill requirements, such as skilled biased technological change (Acemoglu and Autor, 2011), or through changes in the demand for entire occupations. This may lead to skill shortages, a situation where jobs are left vacant, because

\footnotetext{
${ }^{3}$ An exception is the recent literature review by Sattinger (2012) we refer to for our definitions of mismatch.
} 
employers in specific sectors cannot find suitably qualified workers (Cedefop, 2010). Analogously, an imbalance could arise in the case of a rapid shift in the labour supply that cannot be easily matched by labour demand, such as a rapid educational upgrading of the labour force (Brunello et al., 2007). In the neoclassical framework, this type of imbalances at the economy level can be explained only as a temporary phenomenon, which might be overcome through labour demand and supply forces.

The real world, as opposed to the neoclassical one, is characterized by frictions that prevent the economy from working perfectly. For instance, both individuals and firms could face problems of imperfect information. Unemployed workers and employers with free vacancies must also search actively in order to find a suitable match. Looking for ads, submitting job applications, screening candidates, carrying out job interviews are all time-consuming processes that are costly for individuals and firms. Moreover, due to imperfect information, it is likely that a worker will accept a job or an employer will hire a worker before finding the optimal one. Models that incorporate costly job search can explain the existence of mismatches in the long run at the economy level. Suboptimal matches at the individual level are only possible temporarily in these models since increasing experience and on-the-job search enables a worker to find an optimal match. In search and matching theory, the match between workers and jobs results from a matching function depending on the unemployment rate and vacancies in the economy (Mortensen and Pissarides, 1999). While the theory can explain why lack of match, such as unemployment or (unfilled) vacancies, and suboptimal matches can take place in the equilibrium because of search costs, it does not formally define the match quality. Jovanovic (1979) describes the worker-job match as an "experience good", whose quality is unknown before the match takes place because of imperfect information on both sides of the market. Over time, the firm becomes more acquainted with the productivity of a worker in the particular job so that a bad match can be detected and turnover takes place. ${ }^{4}$ Moreover, Jovanovic's model predicts that each worker's separation probability is a decreasing function of their job tenure because a mismatch between a worker and a job is likely to be detected early on rather than late. Therefore, employment duration has often been used empirically as a measure of match quality (Bowlus, 1995).

Search theory defines job-worker match without explicitly taking into account qualitative differences in the characteristics among workers and job. From an empirical point of view, however, it is crucial to open the "black box" of job match and to focus on the characteristics that distinguish a "good" match from a "bad" match. Other economic models, often referred to as assignment models, allow for heterogeneity in worker's and job's characteristics explicitly (Sattinger, 1993). In this type of model, the employee's productivity does not only depend on the individual human capital, but also on the match quality between the individual characteristics and job tasks, and varies from job to job. In this

\footnotetext{
${ }^{4}$ Turnover can also result from a choice of the worker since he receives information about other jobs over time.
} 
context, the problem for the manager (or central planner) is that of determining how to assign jobs to workers in order to maximize production. Models combining assignment with costly search have shown that mismatch can be a long-lasting phenomenon at the individual level (Albrecht and Vroman, 2002; Teulings and Gautier, 2004; Dolado et al., 2009).

\subsection{Employee's Perspective}

From the perspective of the employee, a match is optimal if the worker cannot get another job that implies a higher utility (Sattinger, 2012). We therefore assume that a worker's employment decision is based on a maximization of the utility associated to the job. In standard neoclassical theory of labour supply, worker's utility depends generally only on (hourly) wages and the hours worked. However, it is likely that other non-monetary characteristics of a job are influential in workers' decisions. The economic literature on compensating wage differentials has already highlighted some of these job-specific attributes, such as repetitive content of jobs, the quality of working conditions, job security, freedom to organise one's own work, degree of supervision and intensity of work (Brown, 1980; Hwang et al., 1992). Other important characteristics include the availability of on-the-job training, the prospect of being promoted, flexibility in working hours, whether the values of the firm match the values of the worker or preferences towards the working environment including the supervisor and colleagues. The geographical location of the job is a further relevant job characteristic at the individual level since many individuals will put a high value to a job close to family and friends.

The degree of utilization of own knowledge and skills could also have a direct impact on worker's utility apart from wages. However, it is unclear in which direction this would affect worker's utility since some workers could judge positively a higher utilization of skills (e.g. through higher self-esteem), while others could have higher effort costs in utilizing their skills. While most empirical studies estimating compensating wage differentials have found relatively small and often insignificant estimates for most job characteristics (Brown, 1980), Hwang et al. (1992) show these estimates to be severely biased downwards because of the failure of taking unobserved heterogeneity into account. This suggests that non-wage characteristics affect worker's job choices more strongly than indicated by the current empirical literature (Hwang et al., 1998).

According to the above definition, the mismatch is always involuntary for the worker in the sense that he would choose a job that implies a higher level of utility if he could. The reasons why this type of mismatch can occur are very similar to those discussed from the perspective of the overall economy. Firstly, because of imperfect information and costly search, the worker will not be aware of all the jobs existing in the economy and it is likely that he will end up in a position that is not the optimal one. Moreover, because of informational asymmetries, an employee will gain full information about the job's characteristics only after having started the job. 
Job satisfaction can be thought as a very natural proxy for the employee's utility resulting from the job. Job satisfaction with respect to different aspects of the job has indeed been found as a good predictor of separation and quit even when wages and working hours are controlled for (Clark, 2001). While some authors have used job satisfaction as a measure of match quality (Ferreira and Taylor, 2011), a potential drawback is that individuals could differ systematically in the way they evaluate job happiness. ${ }^{5}$ Another possible measure of mismatch from the employee's perspective is whether he is looking actively for another job since on-the-job search is a direct evidence that the worker does not consider the match to be optimal (Allen and van der Velden, 2001).

The employee perspective distinguishes itself from the overall economy perspective in several respects. The first one is that some workers may prefer a job where they do not yield the maximum productivity. If using skills at work requires some effort and there is heterogeneity in the cost of effort, the workers with higher effort costs will prefer a job with a lower level of productivity and compensation. ${ }^{6}$ Thus, it could be the case that workers and jobs will not be optimally paired to reach the maximum productivity. The second argument builds also on the heterogeneity in individual preferences with regard to job characteristics. The theory of compensating wage differentials predicts that "prices" of non-wage characteristics are fully reflected in wages, but this can hold only if there is no heterogeneity on workers' tastes. While some of the job attributes (such as fringe benefits) can be bargained upon by firms and workers, others are fixed for a firm or very costly to change (such as firm values). Wage and other non-wage compensations could not fully reflect productivity in the real world, and thus workers could have an incentive to accept a job that is not the optimal one from the economy perspective. The third argument deals with worker's preferences concerning the geographical location of a job and with the mobility costs related to it. Literature on migration has stressed the relevance of mobility costs, also psychological ones, and the importance of taking into account individual preferences in migration decisions (Hunt and Mueller, 2004). Preferences and costs related to geographical mobility can be particularly influential for specific socioeconomic groups. For instance, it has been claimed that married women are more likely to be mismatched in terms of skills and education because they are relatively immobile (Frank, 1978). This would occur because couples search for jobs in the same local labour market and a higher priority would be typically given to the job of the male partner (since he is generally the primary earner). It is therefore plausible that many individuals would choose a job close to their family or friends, despite this not being the optimal match from a productivity point of view.

\footnotetext{
${ }^{5}$ Clark and Oswald (1996) for example show that holding income constant job satisfaction declines with education.

${ }^{6}$ Similarly, Leuven and Oosterbeek (2011) claim that people may differ in the degree to which they value leisure on the job.
} 


\subsection{Employer's Perspective}

From an employer's perspective, a mismatch would occur if an employed worker could be replaced by a different employee yielding a greater productivity at an unchanged wage rate (Sattinger, 2012). As explained above, this situation can arise because of imperfect information about the applicant's characteristics and search costs for the employer (e.g. leaving vacancies unfilled or costs for job advertisements). For a given vacancy, the employer has to decide whether to choose one of the available applicants or to engage in further search. If search costs are not outweighed by the probability to find a better matching applicant, the employer will stop the search process and hire the applicant promising the highest productivity. For the selection decision, the employer has to infer the productivity from a comparison of the applicant's observable characteristics and job requirements. The most common selection approach analysed in economic literature is the comparison of the worker's knowledge, skills and abilities with the job's requirements. This approach implies that the productivity is only determined by the appropriateness of these factors for the given job.

The human resource management literature examines further dimensions of the job match influencing the level of productivity or related outcomes, such as satisfaction or motivation (Jansen and Kristof-Brown, 2006). ${ }^{7}$ Several authors analyse the 'personenvironment fit' based on the assumption that the productivity of a worker is determined by the interaction of the worker with the employment environment. The employment environment comprises all conditions of a particular position which can be task-related or not. Muchinsky and Monahan (1987) proposed two distinct conceptualizations of the person-environment fit. First, a complementary fit occurs if either individual skills meet the environmental needs (demands-abilities fit) or individual's needs are met by environmental supplies (needs-supplies fit). This implies that there is a gap in the needs of either the worker or the employer, which is closed by the emerging match if no mismatch occurs. Supplementary fit is the second conceptualization of fit and occurs if the individual and the environment are similar.

The concept of person-environment fit has been decomposed into different dimensions (see the review of Jansen and Kristof-Brown, 2006). The person-job fit reflects to what extent the worker's characteristics meet the job's requirements for being able to accurately perform the job tasks. Other dimensions of the person-environment fit highlight that the productivity is not only determined by the suitability of skills. The person-organization fit describes to what extent a worker matches the characteristics of an organization, such as values or organizational culture (Bowen et al., 1991). The person-group and personsupervisor fit examine the productivity effects of the worker's interaction with his working group and his supervisor. The meta-analysis of Kristof-Brown et al. (2005) analyses the effects of the different match dimensions on work-related outcomes. In total, the

\footnotetext{
${ }^{7}$ While the results of the human resource management literature are relevant to all three perspectives, they are described in this section because the literature focuses especially on the employer's point of view.
} 
authors employed results of 172 (case-)studies containing information on the different fit measures and productivity-related outcome variables as well as tenure. They find that all dimensions positively affect overall performance, job satisfaction and tenure. The highest positive impact is found for the person-job fit. The findings suggest that the adequacy of the worker's skills for the job tasks is not the only determinant of productivity, though it is the most important of the tested dimensions of fit.

From an employer's perspective, there can be diverse causes for hiring a worker who does not match the job's requirements perfectly. In a world with costly search and imperfect information, the incidence of mismatch in a firm will be strongly affected by the quality of the firm's recruitment and selection practices in forecasting the applicant's productivity (Cedefop, 2012). As outlined above, the human resource management literature has established a variety of interdependent dimensions of job match quality. Even if the applicant's characteristics could be identified perfectly during the recruitment process, his later performance would be determined by the firm's environment. If the firm needs to introduce organizational changes, for instance in order to adapt to technological change or changing job tasks (Spitz-Oener, 2006), the worker's productivity could be affected negatively since the person-environment fit changes. Similarly, Lazear (1998) states that employers also have to consider the uncertainty of the future suitability of an applicant's skills for firm productivity in addition to the skills an applicant possesses at the time of recruitment. Another situation which produces mismatches while the applicant's skills can be observed perfectly arises if skill shortage is present (Cedefop, 2010). In this case, there are no individuals in the economy having at least the required skill level for performing a given vacant job. A mismatch occurs if the employer faces higher costs for leaving the job vacant than for hiring a mismatched worker and subsequent training. The duration of mismatches within a firm will then be highly correlated with the persistence of skill shortage in the economy.

In general, the employer's incentive to form matches promising the highest possible productivity given the tasks of the job reflects an optimal decision rule from an overall economy perspective. From both perspectives, a given match will be optimal if no productivity losses occur. However, there are two cases where an employer regards a match as being optimal while, from an overall economy perspective, a mismatch occurs. First, for an employer it is irrelevant if another job outside the own firm exists allowing a higher productivity for his applicant. Second, employers can hire workers with higher skills than the job requires in order to ensure a continuous and uninterrupted supply of high skills to a firm (Cedefop, 2012). Desjardins and Rubenson (2011) argue that this insurance strategy could be optimal for firms facing rapidly changing markets and high uncertainty with respect to future labour adaptations. This strategy will produce mismatches from an economy perspective because these workers could yield a higher productivity in another job. 


\section{Empirical Literature on Qualification and Skill Mis- match}

\subsection{Measures for Qualification and Skill Mismatch}

Most of the empirical economic literature on job-worker mismatch focuses on the mismatch between the formal education possessed by a worker and the one required for the job. One explanation of the focus on educational mismatch is that the estimation of returns to schooling has been a major topic of interest in labour economics in the last decades. Given that education is heavily subsidized in most developed countries, there is clearly a concern of a possible overinvestment in education. In the 1970s, several authors reported a decrease in the returns to university education in the United States in response to a strong increase in the number of university graduates. Great attention was especially raised by the book "The Overeducated American" (Freeman, 1976), in which the author claims the presence of an oversupply of college graduates with a long lasting decrease in returns to college education. Although the persistence of such an imbalance between overall supply and demand of education was proven to be wrong (Smith and Welch, 1978), Freeman's analysis gave rise to an extensive set of studies analysing educational mismatches at the individual level (for example Duncan and Hoffman, 1982). These studies focused mainly on overeducation or overqualification, indicating that the level of qualification possessed by the worker is higher than the one required for the job.

Three main sets of measures for qualification mismatch have been used in the literature varying in the way they determine the educational level required by the job. The first method is based on workers' self-assessment about the educational requirements of the job. An individual is considered to be mismatched if he has an educational level, which is higher or lower than the one he reports to be required by the job. The exact phrasing of the sentence differs across studies and can lead to different empirical results if for instance "credentialism" is present (Sloane, 2003). In this case, the required qualification to get a job is higher than the required qualification to perform a job. Since the method relies on workers' self-assessment, there might be concerns about the subjectivity of the measure. Hartog (2000), for instance, points out that respondents may have the tendency to overstate the requirements of their job, leading to a measurement error, which might well be correlated with worker's education.

The second method relies on information contained in occupational classifications to measure required schooling levels. The job analysis or objective measure is based on a systematic evaluation by professional job analysts who specify the required level of education for the job titles in the occupational classification. The most commonly used example is the Dictionary of Occupational Titles (DOT) in the United States (Rumberger, 1987), which by now has been replaced by O*NET (Converse et al., 2004). While this method has the advantage of explicitly trying to achieve objectivity, the main drawbacks 
are that it does not allow for differences in required schooling within occupations and that updates of the classifications are rather infrequent (Leuven and Oosterbeek, 2011).

A third approach used in the literature uses information from realized matches by looking at the distribution of educational qualifications possessed by workers within a given occupation. Employees are generally defined as mismatched if they have a level of schooling deviating more than a standard deviation from the mean or mode (Verdugo and Verdugo, 1989; Bauer, 2002). This statistical measure again has the drawback that the required level of education is assumed to be homogeneous within occupations. Moreover, this mismatch measure is derived from the actual employees' educational level, which does not reflect the level of education required by the job (Hartog, 2000). The meta-analysis of 25 econometric studies on overqualification by Groot and Maassen van den Brink (2000) reveals differences in the incidence and wage consequences of overeducation across studies and measures used. The literature does not provide a clear guidance which method should be preferred in practice. Since these measures are found to correlate imperfectly, measurement error is clearly a concern in any empirical analysis (Leuven and Oosterbeek, 2011). For analysing job mismatch among German employees, the objective measure cannot be used since job analyst ratings similar to DOT or O*NET are not available for Germany. While the statistical measure can be derived from information about a respondent's educational qualification and occupation, a direct question concerning the qualification requirements is crucial for employing the self-assessment measure.

Apart from measurement issues, it is also not clear whether qualification mismatch is the right concept to analyse suboptimal job-worker match from an overall economy perspective. Most papers assume that qualification mismatch measures the discrepancy between the skills of the individual and the skills required by the job (Quintini, 2011). However, in many cases qualification mismatch is a very imperfect proxy for mismatch in job-relevant knowledge, skills and abilities. Workers holding the same qualification can be very heterogeneous with respect to the amount and type of skill possessed. First of all, while the skills and knowledge acquired in formal education are one of the most important inputs for job-related skills, they are not the only ones. Personality traits or innate ability are also productivity-related factors and obviously vary between individuals holding the same qualification. Moreover, individuals holding the same degree can benefit in a different level from their education, depending for example on the effort they will put in their studies. For these reasons, the existence of qualification mismatch can be consistent with human capital theory in a neoclassical context if the individual differences in skills unrelated to formal education compensate for the differences in terms of qualifications (Hartog, 2000). In this case, it would not imply a suboptimal outcome and would therefore be a measure of limited interest for our purposes.

The questions of whether there is an overinvestment in education and of whether there is mismatch implying productivity losses are different, even if there could be a relationship between the two. Most of the literature on overeducation focuses on answering 
the second question, even if this is often not stated explicitly. In particular, the major aim of the overeducation literature has been to estimate the effects of qualification mismatch on wages, where the latter are assumed to reflect productivity or to be a valid proxy for it. Most studies find that overeducated individuals earn more than well-matched co-workers holding a lower qualification, but less than well-matched study colleagues (reviewed by Leuven and Oosterbeek, 2011). However, as stated above, some of this wage difference might be ascribed to the heterogeneity in worker's ability. Bauer (2002) employs a fixed effects estimator using the German Socio-Economic Panel and finds that wage effects of overeducation become much smaller or disappear when individual heterogeneity is controlled for. Similar results were found by subsequent research using panel data (Frenette, 2004; Korpi and Tåhlin, 2009; Tsai, 2010).

Even if these studies have the advantage of directly addressing the endogeneity problem resulting from unobserved heterogeneity, fixed effects techniques do have potential drawbacks in this context. Since changes in overeducation are mostly implied by job changes, there might be time-varying unobservables affecting wages associated to these changes (Leuven and Oosterbeek, 2011). Moreover, the identification relies on the exogeneity of the transition between match and mismatch, which might be problematic since the likelihood of moving to a matched job is not a random process (Chevalier, 2003). The recent review of Leuven and Oosterbeek (2011) concludes that the overeducation literature has not yet succeeded in addressing the bias resulting from omitted variables, such as unobservable skills and ability, in a satisfying way.

Several papers have analysed the effect of qualification mismatch on job satisfaction finding that overqualified workers are less satisfied with their job than matched workers (Tsang, 1987; Büchel, 2002; Verhaest and Omey, 2006). In Section 2.2, we suggested that job satisfaction might be a good indicator for a worker's utility and might be used for analysing the mismatches from the perspective of the employee. Moreover, we underlined that it could also be an indicator for job productivity as suggested by the human resource management literature and by several papers on overeducation (Tsang, 1987; Büchel, 2002). It is difficult to say if the endogeneity problem is less severe in an equation having job satisfaction as dependent variable instead of wages. First, it could be the case that happy people are more likely to obtain better jobs (Clark et al., 2008). Second, since empirical studies typically find a positive relationship between wages and satisfaction, the failure to control for worker's ability might be a relevant issue also in the satisfaction equation. However, this second issue does not seem to be too much of a problem since most studies find that overqualified workers are less satisfied than well-matched workers in the same job, who typically receive lower wages (Hersch, 1991; Tsang et al., 1991; Verhaest and Omey, 2006).

Recently, an increasing number of studies have employed direct information on perceived skill mismatch resulting from workers' self-assessments (Allen and van der Velden, 2001; Green and McIntosh, 2007; Quintini, 2011). Skill mismatch occurs if an employee 
possesses different skills or a higher/lower level of skills than required to perform a job. According to our definition of mismatch from the perspective of the overall economy, skill mismatch only implies a suboptimal outcome if it occurs in those skills affecting job productivity. Most of the empirical studies employ self-reported measures for skill mismatch that do not define explicitly what skills are accounted for. Skill mismatch is most frequently measured by individuals' responses to a direct question concerning the match between the skills possessed and required. Questions used differ between datasets complicating the comparison of studies. Allen and van der Velden (2001) construct a measure of skill mismatch based on the question asking to what extent workers can use their knowledge and skills in their job. They find a positive relation between this measure of skill mismatch and the self-assessment measure of qualification mismatch. However, a notable share of overqualified graduates does not indicate an underutilization of skills while skill mismatch is present among qualification matched graduates. The authors conclude that overqualification increases the likelihood to be skill mismatched but that both measures do not correlate perfectly. They also find that skill mismatch has a negative effect on wages and job satisfaction. While qualification mismatch appears to affect wages in a stronger way, skill mismatch is found to be a much better predictor of job satisfaction.

Since individuals holding equal qualifications can be heterogeneous in their abilities, several studies try to measure mismatch by either combining overqualification with skill mismatch or overqualification with job satisfaction (Chevalier, 2003; Green and Zhu, 2010). The reason is that less able workers could end up in jobs requiring a lower qualification, while the job matches their skills. Thus, two types of overqualified workers exist depending on the utilization of skills. Workers in the first group do not indicate skill mismatch, while the second group consists of workers obtaining a higher level of skills than required for their job. If productivity is determined by the match between job tasks and worker's skills, overqualification alone does not have to imply productivity losses. At the same time, this situation could reflect a waste of educational resources from the overall economy perspective because the worker did not learn the required knowledge in educational training. Chevalier (2003) divides overeducated workers in two groups depending on the reported satisfaction with the match between education and job. Graduates working in a non-graduate job are considered "apparently" overeducated if they are satisfied with the match. In contrast, "genuinely" overeducated graduates are those who are dissatisfied with having a non-graduate job. A similar approach was conducted by Green and Zhu (2010), who use the combination of qualification mismatch and skill mismatch to distinguish between "formal" and "real" overqualification. Differently from "formal" overqualified workers, "real" overqualified workers report to underutilize their skills in the job. They find higher wage penalties and lower satisfaction for "real" overqualified workers than for "formal" overqualified workers. 


\subsection{Determinants of Qualification and Skill Mismatch}

Studies analysing possible predictors of job mismatches have focused on several explanatory variables for the occurrence of job mismatch (mainly measured in terms of overqualification). Socio-demographic characteristics, such as age, ethnicity, gender, marital status and children, have been widely examined as possible determinants of mismatch in different countries. Most studies find that young people, women and migrants are more likely to be mismatched (Leuven and Oosterbeek, 2011). The higher incidence of mismatch among women has been addressed by Frank (1978), who explains the empirical findings through the limited geographic mobility of married women compared to men. According to Frank's theory of differential overqualification families would give a higher priority to the job of the primary earner, who is generally the man. If there is no adequate job for women located close enough to the one of their partner, they would need to accept the second best option of a suboptimal job match. More recent tests of the theory of differential overqualification have given mixed results. McGoldrick and Robst (1996) did not find evidence of a relationship between the labour market size and the likelihood of women being overeducated. On the contrary, Büchel and Battu (2003) showed that married women in Germany run a high risk of being overeducated, especially when they live in rural areas.

Quintini (2011) finds that the likelihood of mismatch is affected by different types of the individual's precedent job separation. Individuals who lost their job involuntarily due to business closure or firing obtain a higher probability of being mismatched than individuals with voluntary job separations. A possible explanation is that these individuals rather accept inadequate job offers than to become or remain unemployed. Another reason suggested by the author is that an involuntary job loss could send a negative signal to potential employers in the future, especially if a spell of unemployment has occurred.

In the context of path dependency of job mismatch at individual level, negative signals for potential employers could also originate in previous inadequate employment. Facing skill heterogeneity of applicants holding the same qualification, an employer could try to infer differences in the amount of human capital from the quality of previous job matches. Since underachievers in ability tests - e.g. in literacy (Quintini, 2011) - have a higher probability of being overqualified, a previous period of overqualification could increase the likelihood of mismatch in the future. Verhaest and van der Velden (2012) examine the likelihood of being overeducated five years after graduation depending on overqualification status six months after graduation and find evidence for relatively high persistence in Germany and other countries. These findings contrast the career mobility theory by Sicherman and Galor (1990), who assume that overqualification is a temporary phenomenon at the individual level. What previous empirical studies focusing on path dependency have not accounted for is self-selection. Since self-selection into inadequate employment over the lifecycle increases persistence in job mismatch independently from market frictions, it is difficult to derive policy implications from existing results. 
Verhaest and van der Velden (2012) show that the incidence of overqualification at the country level, as well as the persistence at the individual level, is affected by cyclical economic fluctuations and structural labour market conditions. Countries experiencing a recession obtain higher overqualification rates for graduates. The same holds for countries with a relative oversupply of highly skilled workers. In the case of tertiary education from an overall economy and educational sector perspective it is relevant to examine the impact of characteristics and organization of study programmes on the likelihood of job mismatch. Literature on this relationship, however, is sparse. Some of the empirical studies focus on the quality or prestige of study programme and institution (McGuinness, 2003; Robst, 1995). Di Pietro and Cutillo (2006) measure university quality by employing performance indicators and find that graduates from research-orientated universities obtain a lower probability of being overqualified. The authors argue that employers could value the "prestige" of the university or that high research orientation could enhance teaching quality providing graduates with the relevant skills to be successful in the labour market. Verhaest and van der Velden (2012) differentiate between general and specific orientation of a study programme. They find that generally educated graduates have a higher likelihood of being overqualified in their first job but lower overqualification persistence than specifically educated graduates. The authors argue that, in line with segmentation theory, graduates of specific programmes enter occupational labour markets with a high likelihood of getting a matching job but with low occupational mobility. In contrast, graduates from general programmes mainly enter internal labour markets with higher probability of internal promotion but lower positions at the career start. Since comparable results for Germany are still lacking, this topic appears to be relevant for further research.

Another underresearched topic is the role of the search intensity on subsequent match quality. While the human resource management literature has studied the process of personnel selection from an employer's side (Searle, 2009; Oyer and Schaefer, 2011), there are very little studies focussing on the impact of a worker's search behaviour on the likelihood of finding a good match. Few studies analyse the impact of different searching channels and find lower match quality if jobs are found through the help of family or friends (Quintini, 2011). However, how match quality is determined by the worker's search intensity, i.e. time spent searching for a job or number of applications, has not been examined so far.

\section{Data and Descriptive Results for German Gradu- ates}

Similarly to other countries, there exists an extensive literature focusing on qualification mismatch in Germany. In particular, several papers have analysed the job match of university graduates finding that qualification mismatch is a potential problem especially for graduates of universities of applied sciences and of specific subjects such as humanities 
or educational sciences (Plicht et al., 1994; Büchel, 1996; Fehse and Kerst, 2007). We contribute to this literature by additionally employing self-reported skill mismatch variables in order to examine how the incidence of job mismatch among German graduates differs according to field of study, gender or type of university. Previous studies mainly concentrate on indirect consequences of job mismatch by analysing effects on wages or the overall job satisfaction. We employ more direct consequences of job mismatches to show how German graduates are affected by overqualification and skill mismatch. We investigate how jobs held by overqualified or skill mismatched graduates differ from jobs of matched graduates with respect to specific job requirements. Both measures are related to the job's level of complexity, pressure, monotony and creativity. Furthermore, detailed information about employees' skill underutilization with respect to a set of specific competences are used to evaluate overqualification and skill mismatch measures used in previous studies. Finally, information about employees' reasons for job choice and the satisfaction with a set of job characteristics are employed to provide first descriptive evidence for self-selection into overqualification for German graduates.

\subsection{Mismatch Measures in German Datasets}

In this section, we identify four German datasets which are particularly suited for analysing job mismatch since measures for qualification and skill mismatch are contained. The first one, BIBB/BAuA, is the 2006 Employee Survey of the Federal Institute for Occupational Safety and Health (Bundesanstalt für Arbeitsschutz und Arbeitsmedizin, BAuA) and the Federal Institute for Vocational Education and Training (Bundesinstitut für Berufsbildung, BIBB). It is a representative survey of about 20,000 employed persons aged between 15 and 70 in Germany and was conducted via computer-assisted telephone interviews (CATI). ${ }^{8}$ In addition to a set of measures for job match quality, the questionnaire contains questions about job characteristics and skill requirements. This enables us to examine differences in jobs depending on match status as measured by qualification or skill mismatch.

The second dataset is the HIS-Graduate Panel 2001, which is a representative survey of German graduates interviewed circa one year ( $1^{\text {st }}$ wave) and five years ( $2^{\text {nd }}$ wave) after their graduation in 2001. ${ }^{9}$ In the first wave, 8,103 graduates were interviewed through postal questionnaires and 5,426 of them (75\% response rate) were re-interviewed in the second wave. Differently from the BIBB/BAuA dataset, the HIS-Graduate Panel includes detailed information on the university study programme and also a question on the reasons for the current employment choice. The third one is a survey covering 15 countries, which was carried out within the framework of the Flexible Professional in the Knowledge Society (REFLEX) project. The sample consists of graduates of the 1999/2000 academic year

\footnotetext{
${ }^{8} \mathrm{BIBB} / \mathrm{BAuA} 2006$ is the most recent of the BIBB Employee Surveys, which were conducted in a similar way in 1979, 1986, 1992, 1999. See Hall (2009) for further information about the 2006 survey.

${ }^{9}$ The survey was carried out by Hochschul-Informations-System GmbH (HIS).
} 
who were interviewed in 2005. Even if only 1,700 German graduates were surveyed, the data are especially interesting because they allow a direct comparison with other European countries. The fourth dataset, KOAB, is not yet publicly available for scientific research. ${ }^{10}$ Nevertheless, we include it in our overview because we find it promising for future research on job mismatch. While the questionnaire is very similar in most aspects to the one of REFLEX, the sample size is much larger in this dataset. 15,200 graduates were surveyed already in the pilot project of 2007 . One year later, the scale of the project had strongly increased reaching a sample of 86,800 graduates, who represent more than $30 \%$ of all German graduates. Among other things, this gives the possibility to analyse the job match of graduates of specific subjects in detail.

\section{Table 1}

Table 1 presents an overview of the four datasets described highlighting variables that we consider particularly relevant to analyse mismatch of German graduates. All four datasets contain self-reported measures of qualification mismatch and job satisfaction, thereby allowing a comparison across datasets concerning these measures. To construct qualification mismatch variables, we employ a question asking the workers what qualification is normally required for their occupation. There are small differences across datasets with respect to this question. Using BIBB/BAuA data we define a graduate to be overqualified if he reports working in a job that requires no university degree. In the "overqualified" dummy resulting from REFLEX data, we include also graduates who work in occupations requiring a university degree of a lower level than possessed. Using HIS data we define graduates to be overqualified if they indicate that the qualification possessed is not required or is not usual in their job.

All datasets with the exception of the HIS data also include one or more self-reported measures of skill mismatch. While these can be contrasted to qualification mismatch variables within the same data, a comparison across datasets is more complicated since the response to these questions largely depends on the particular formulation. BIBB/BAuA data allows us to employ two measures for skill mismatch. The first one is derived from a question asking whether the worker feels unchallenged with respect to the professional knowledge and skill requirements in his job. ${ }^{11}$ The second variable is constructed from a question asking how much of the occupational knowledge and skills acquired during the vocational education can be utilized in the current job. ${ }^{12}$ REFLEX data contain also a direct question on the utilization of knowledge and skills in the current work. We construct a dummy variable for skill underutilization (overskilled) similarly as with BIBB/BAuA

\footnotetext{
${ }^{10} \mathrm{KOAB}$ (Kooperationsprojekt Absolventenstudien) is a joint research project of the Kassel International Centre for Higher Education Research (INCHER-Kassel) and various higher education institutions in Germany.

${ }^{11}$ The dummy variable "unchallenged" takes a value of one if the respondent states to feel unchallenged and zero otherwise.

${ }^{12}$ The dummy variable "underutilization of skills" takes the value one if the respondent indicates that he can use very little or little of this knowledge and skills.
} 
data. However, this measure is more general since it is not restricted to knowledge and skills acquired during formal education. HIS, REFLEX and KOAB data additionally contain very detailed information about the underutilization of specific competences required by the job (such as mastery of own field, analytical thinking, ability to rapidly acquire new knowledge or ability to work productively with others). For every competence, the respondent has to indicate the importance for his job and the level possessed using a seven-point Likert scale. These questions allow us to construct mismatch variables that are more detailed than a direct question on general skill mismatch. Analyses of skill mismatch or productivity effects of job mismatch could be conducted more precisely using these measures. Using REFLEX data, we construct dummy variables for every competence indicating whether a worker holds a skill surplus, a skill deficit or the appropriate level of skills.

As suggested by the human resource management literature examined in Section 2.3, productivity could also hinge on the matching of the individual's preferences for and the supply of particular job characteristics. REFLEX and KOAB data include questions about job characteristics potentially valuable to workers such as work autonomy, social status or opportunity to learn new things. Similarly to the questions on specific skills, the respondent indicates how important each specific attribute is for himself and to what extent it applies to the current job, respectively. Besides adding a new dimension of job mismatch to the empirical literature, this information could be used to examine motives for a voluntary qualification or skill mismatch at the individual level. For instance, responses to attributes like "enough time for leisure activities" or "good chance to combine work with family tasks" could be employed to examine self-selection into qualification or skill mismatch.

Column 3 and 4 of Table 1 show information about selected determinants of job mismatch which are particularly interesting in our view. HIS, REFLEX and KOAB data include detailed information on the study programme of the interviewed graduates, such as the emphasis on different teaching methods or compulsory internships. Moreover, all datasets apart from BIBB/BAuA include a question where graduates have to evaluate their study programme. The respondents are asked whether they would choose the same study programme again, another study programme or would not study at all, if they were free to choose with today's information. This information could be very interesting with respect to mismatch research for two reasons. First, it could contain some information for assessing the problem of self-selection into inadequate employment. If respondents, for instance, acquire a tertiary degree as part of an insurance strategy against unemployment, they would probably indicate that studying was right even if they are overqualified. In contrast, individuals being involuntarily mismatched would probably conclude that studying did not pay off. Second, previous measures of job match quality do not take education costs into account. It could be reasonable to assume that individuals compare investments into tertiary education with the utility obtained from having a degree. 
The role of an individual's search strategy for finding a good match has not been examined so far. The presented datasets contain questions about the search intensity such as number of applications or total time spent searching for a job. Moreover, HIS and $\mathrm{KOAB}$ data include questions asking the reasons for accepting the current job. This information could be used for analysing self-selection into job mismatch, so that employees are voluntarily mismatched from an overall economy perspective.

\subsection{Incidence of Job Mismatch Among German Graduates}

Using qualification and skill mismatch variables, this section provides descriptive results for the incidence of job-worker mismatches in Germany according to gender, field of study and type of university. As a starting point, we carry out an international comparison of mismatch shares using REFLEX data. Table 2 shows the incidence of qualification and skill mismatch in selected European countries. The figures refer to individuals who are employed five years after graduation. Graduates in self-employment are excluded from this analysis. A graduate is defined as overqualified if his job merely requires vocational education or he holds a higher tertiary degree than the one most appropriate for his job. If a graduate is working in a job requiring a higher tertiary degree than he possesses, he is defined as underqualified.

\section{Table 2}

In all presented countries, a higher share of graduates is affected by overqualification than by underqualification. In Germany, roughly 16 percent of graduates are overqualified, while 7 percent are underqualified. For south European countries, i.e. Spain and Italy, but also for UK and Belgium, we find significantly higher shares of overqualification. The only country possessing a significantly lower share of overqualification among graduates is Finland (10 percent). Underqualification rates vary less between countries and range from 11 percent (Norway) to 5 percent (the Netherlands). The collectively low share of underqualification could be explained by the fact that only individuals holding a high qualification are sampled.

We employ two direct questions in the REFLEX data for measuring skill mismatch. First, respondents have to indicate to what extent the own knowledge and skills can be utilized in the current job on a five-point Likert scale. Graduates merely using a low or very low extent of own skills are defined as overskilled. Second, respondents are asked to what extent the current job demands more knowledge and skills than they possess. If a graduate indicates that more skills are required than he can actually offer, he is considered underskilled. Comparing these types of skill mismatch, we see that the share of underskilled graduates is significantly higher in all countries and shows only minor variation across countries. This result is in line with the analysis of Allen and van der Velden (2001). The authors also show that underskilling has hardly any effect on wages or job satisfaction. 
In Germany, roughly 9 percent of graduates are overskilled and can use their own knowledge and skills only to a low extent. Shares of overskilling are significantly higher in Spain, Italy and the UK, but significantly lower in Norway and Finland. In all presented countries, overqualification occurs more frequently than overskilling. In fact, overqualification rates are twice as high as overskilling rates in most countries.

Even if the incidence of job mismatch seems to be relatively low for German graduates in general, some subgroups of graduates could be more strongly affected. It is therefore interesting to investigate the incidence of mismatch for specific subgroups making use of a larger dataset. Table 3 shows the incidence of overqualification of German graduates by subject of study, type of university and gender using HIS data. The total share of overqualified graduates amounts to 16 percent and is very similar to the result found using REFLEX data. Both datasets focus on graduates from universities or universities of applied sciences interviewed about five years after graduation. The year of graduation is also very closed in both datasets (the 1999/2000 academic year in REFLEX data and the 2000/2001 academic year in HIS data).

\section{Table 3}

There are strong differences in the amount of overqualification depending on the field of study. In Germany, students of the subjects medicine and health, teaching and law have to take a state examination at the end of their studies. For each discipline, these state examinations are a prerequisite for holding a civil service job or a job regulated by the state. In particular, students of the subjects medicine and health, and teaching obtain a strongly limited job choice after graduation. They are qualified only for jobs within their own profession and thus act on a highly specialized labour market. Due to governmental regulated access restrictions, graduates of these subjects cannot be overqualified if they hold a job within their own profession. According to this, we find that percentage shares of overqualified employed graduates in the subjects medicine and health (1 percent) and teaching (2 percent) are the lowest within all subjects. Graduates of the subjects law and mathematics, science and computing exhibit a fairly low overqualification rate (circa 10 percent). The share of overqualified workers is substantially higher in all other fields with engineering and construction in a middle position. In the fields of social and behavioural sciences, humanities and arts, and business and economics the overall share of overqualification amounts to 27 percent.

However, the high overqualification rate among business graduates is strongly ascribed to graduates from universities of applied sciences, who are twice as likely to be affected by overqualification as university graduates. For most of the subjects, we find a higher rate of overqualification for graduates from universities of applied sciences except for social and behavioural sciences. This finding is consistent with previous evidence for Germany (Plicht et al., 1994; Büchel, 1996). Studies comparing the revenues of German institutions of tertiary education find higher earnings for university graduates than for 
graduates from universities of applied sciences (Riphahn et al., 2010). We find a higher likelihood of ending up in overqualification for the latter group. To a certain degree, this could explain the wage differences found in those studies since overqualification seems to induce wage penalties (Leuven and Oosterbeek, 2011). In Table 3, we additionally compare overqualification rates according to gender and find that female graduates on average are more likely to be overqualified (18 percent) than men (14 percent). This gender gap is present in all fields of study (with the exception of law) and therefore does not result from an overrepresentation of women in subjects with a higher risk of overqualification.

In the following paragraph, we will additionally provide statistics on the incidence of skill mismatch among German graduates by field of study (Table 4). For measuring skill mismatch, we employ two questions from the BIBB/BAuA dataset. First, graduates are defined as "unchallenged" if they indicate to feel unchallenged with respect to the professional knowledge and skill requirements in their current job. Second, "skill underutilization" is present if graduates can only use little or very little of the occupational knowledge and skills they acquired during their study programme. Since this variable directly accounts for the difference of skills acquired during the study program and skills required by the job, these findings could raise questions about the appropriateness of the content of different study programmes for the labour market.

\section{Table 4}

Before commenting on the incidence of skill mismatch, we show how robust the findings concerning overqualification using HIS are if another dataset is employed. In the REFLEX and the HIS data, graduates are observed at an early point of their career (five years after graduation). In contrast, the Employee Survey conducted by BIBB/BAuA covers graduates in different stages of their lifecycle. We find a higher overall overqualification incidence in the BIBB/BAuA sample (20 percent) than in HIS and REFLEX (16 percent). This fact is surprising given that the workers' average age in the BIBB/BAuA sample is higher than in the HIS sample and that older workers are generally less likely to be overqualified than younger colleagues (Leuven and Oosterbeek, 2011). ${ }^{13}$ Figure 1 shows the share of mismatched workers in the BIBB/BAuA sample by experience cohorts, where experience is defined as the number of years since graduation. The first figure shows that, with the exception of workers with less than three years of experience, the relationship between overqualification and the number of years since graduation is inverted U-shaped. Workers interviewed four to six years after graduation are comparable to the graduates sampled in HIS data in terms of age and the stage of the career. This group of graduates exhibits the lowest overqualification share (about 16 percent). This result could also indicate that the overqualification rate for Germany found in Table 2 could depend on the particular age group considered since most studies generally find a strong negative

\footnotetext{
${ }^{13}$ On average, workers are 44 years old in the BIBB/BAuA sample and 33 years old in the HIS sample.
} 
relationship in other countries between age and overqualification. Although the overqualification rates are higher in the $\mathrm{BIBB} / \mathrm{BAuA}$ sample, the ranking of subjects is nearly unaffected when different datasets are employed. Again, among other subjects, graduates of business and economics have a high risk of being overqualified, while graduates in the fields medicine and health, and teaching hold matching jobs most frequently.

Turning to skill mismatch, the employed data suggest that the likelihood of underutilizing own professional skills in the job (19 percent) is higher than the likelihood of feeling unchallenged (10 percent). Subject-specific differences in the amount of skill mismatch are smaller for the measure "unchallenged" than for "underutilization of skills". MINT graduates seem to be relatively often skill mismatched according to the underutilization of own skills (21 to 25 percent), but only 9 percent of them indicate to feel unchallenged in their job. The highest share of unchallenged graduates are found for the subject humanities and arts (16 percent). In Figure 1, we examine whether our skill mismatch variables are related to the stage of the career a graduate is observed at. The second graph shows the percentage share of employees feeling unchallenged depending on the years elapsed since graduation. The highest share of 15 percent is observed for graduates at the beginning of their career ( 1 to 3 years after graduation). In later stages of the lifecycle, the share is relatively persistent at 10 percent but drops to 8 percent if more than 19 years since graduation have elapsed. The relation of "skill underutilization" and time since graduation is shown in the third graph. Here we find the opposite trend, if anything, with older workers utilizing the skills acquired during education less than their younger colleagues. An intuitive explanation for this is that, over the years, workers learn more skills on-the-job and utilize these more frequently than skills acquired during education. It could also be the case that skills acquired during education are affected by a certain degree of depreciation.

\subsection{Surplus and Deficit of Job-Relevant Competences}

In the previous sections, we have stressed that qualification mismatch variables can only measure skill mismatch imperfectly since they do not take into account heterogeneity in the effective skills possessed by graduates. We underlined that a direct question concerning the underutilization of the own skills could measure productivity related job mismatch better. According to such a question, workers are considered as being skill mismatched if they indicate that their own skills can be utilized only to a low degree in the current job. Since skills are not precisely defined in this type of question, it is unclear which specific skills are underutilized by graduates indicating that they are skill mismatched.

To shed some light on this, we employ a set of detailed questions from the REFLEX data concerning a set of 19 job-relevant competences. This set covers a variety of competences which could be required for fulfilling a job effectively. In addition to the mastery of the own field, we employ information on competences that could determine how productive a graduate is in his job. Competences such as analytical thinking, rapidly acquiring 
new knowledge, performing well under pressure or using time effectively could be relevant for completing job tasks. Since employees are working in groups in most occupations, it could also be crucial that workers are able to work productively with others or to make the own meaning clear to others. Especially for graduates holding a managerial position, it is important to what extent they can mobilize the capacities of others or assert the own authority. Innovations are an important driver of economic growth and crucial for most firms to remain competitive. The likelihood of realising innovations at the firm level could hinge on the ability of employees to come up with new ideas and solutions, the willingness to question own and other's ideas or the alertness to new opportunities.

For every competence, the respondent has to indicate the level he possesses and the level that is required for the job on a seven-point Likert scale ranging from "very low" to "very high". By computing the difference $(D)$ between the level possessed and the level required we can infer skill surplus and skill deficit in job-relevant competences for German graduates at the individual level. If a respondent indicates an own level of 1 (very low) and a required level of 7 (very high), the difference takes the lowest possible value $(D=-6)$. The highest possible value of the difference $(D=6)$ is computed for respondents indicating an own level of 7 (very high) and a required level of 1 (very low). We consider a graduate to have a surplus in a given competence if he indicates a higher own level than required level, and the difference takes a value higher than or equal 2. In a similar way, we consider a graduate to have a skill deficit if he indicates a lower own competence level than the level that is required, and the difference takes a value lower than or equal -2 . Thus, we define graduates to have an appropriate level of skills in a given competence if the difference between own level and required level takes the value $-1,0$ or 1 . The share of graduates having a surplus, a deficit or the right amount of skills in 19 job-relevant competences are provided in Table 5.

\section{Table 5}

We find that 10 percent of graduates possess a higher level of mastery of own field than required by their job (column 1). Substantial shares of graduates seem to have a surplus of competences, where the highest share is found for writing/speaking in a foreign language (31 percent). Performing well under pressure and using time effectively exhibit the lowest shares of surplus ( 9 and 10 percent). For competences being relevant for working in groups, holding managerial positions or enabling innovations we find surpluses for 14 to 24 percent of graduates. In general, the share of graduates indicating a skill deficit (column 3) in a given competence is lower than the share indicating a surplus. We find a lower share for surplus (10 percent) than for deficit (16 percent) only for the effective usage of time. In addition, graduates indicate substantial skill deficits for some competences, such as performing well under pressure, negotiating effectively and asserting authority. However, the shares of graduates indicating deficits in job-relevant competences are much lower than the share that indicates being underskilled answering broad skill mismatch question 
provided in Table 2 (26 percent). For competence surpluses, we find the opposite, so that surpluses are more often indicated than being overskilled according to a direct skill mismatch question (9 percent).

In the following paragraph, we will analyse to what extent surpluses in job-relevant competences are related to a skill mismatch measure, which is usually employed in the literature. This skill mismatch measure is derived from a direct question. Graduates indicating that own knowledge and skills can merely be utilized to a low degree are defined as being overskilled. Since skills are not specified in this type of question, we take a first step to infer its appropriateness in measuring surpluses in job-relevant competences. Similarly, we examine to what extent qualification mismatch is related to surpluses in competences.

Table 6 provides the shares of matched graduates and overqualified graduates indicating a surplus in a given competence. We find that 9 percent of matched graduates obtain a higher level of mastery of own field than required for the job (column 1), while this is the case for 18 percent of overqualified graduates (column 2). For 9 out of the 19 competences, we find that overqualified graduates indicate a surplus significantly more often than matched graduates. Mean differences of the share of matched graduates and overqualified graduates having a surplus are provided in column 3. These results indicate that overqualified graduates are more likely to have a surplus in job-relevant competences, such as analytical thinking, coordinating activities or presenting products and ideas, than graduates holding a job matching their qualification.

\section{Table 6}

Turning to skill mismatch, we find that 8 percent of matched graduates indicate a surplus in the mastery of own field (column 4), whereas 30 percent of overskilled graduates have a surplus in this competence (column 5). For every competence, the percentage share of graduates indicating a surplus is higher among overskilled graduates than among matched graduates. Except for the three competences knowledge of other fields, perform well under pressure, and coordinate activities, the mean differences in column 6 are significantly different from zero for all competences.

By comparing very detailed information about surpluses in job-relevant competences with a broad measure of skill mismatch usually employed in the mismatch literature, we find two striking results. First, substantial shares of graduates that are not skill mismatched according to the widely used direct measure possess surpluses in a variety of job-relevant competences (column 4). For instance, 14 percent of theses graduates indicate to hold a higher level in analytical thinking or the ability to rapidly acquire new knowledge than is required by their job. Since knowledge and skill requirements of jobs are multidimensional, information seems to be lost if a direct broad question is employed to measure skill mismatch. Using the information about surpluses in specific relevant competences could improve further research, i.e. for causal analyses concerning productivity effects of skill mismatch. 
Second, we find that surpluses in competences are more strongly related to the direct skill mismatch measure than to overqualification. To the extent that surpluses are relevant for job productivity and that concerns about the subjectivity of self-ratings of skill underutilization are not too high, the direct skill mismatch measure would be a better predictor for job mismatches from an overall economy perspective than overqualification.

\subsection{Job Characteristics Depending on Job Match Quality}

In this section, we employ information about job requirements to show how job quality is related to qualification and skill mismatch. This is a further step to analyse the consequences of job mismatch for German graduates. In the BIBB/BAuA dataset, respondents provide detailed information concerning diverse job characteristics. In the 2006 wave of the Employee Survey, respondents had to indicate how often a given set of specific job requirements were needed in their current job using a three-point Likert scale. Possible answers included the categories "frequently", "sometimes" and "never". In the following section, we will examine how jobs of matched graduates differ from jobs of mismatched graduates in terms of these specific job requirements. These measures allow us to investigate job differences in a more direct way than through wages and job satisfaction, which can be considered as rather indirect consequences of the job match.

We examine four different dimensions of job characteristics for measuring how challenging a job is (see Table 7). The first dimension ("complexity") measures to what extent key qualifications are required for the job. Key qualifications are defined as general skills enabling somebody to exploit rapidly changing expert knowledge and to improve the ability to solve problems (Hall, 2009). For measuring the complexity level of a job, we use six questions concerning key qualification requirements, i.e. how often a respondent has to solve problems or close own knowledge gaps. The second dimension ("pressure") describes how frequently respondents have to work very fast, work under pressure to perform and reach their own capacity limit. To what extent job tasks are prescribed and repeating in every detail indicates the level of "monotony" a job exhibits. The requirements in the fourth dimension ("creativity") are measured using three items indicating how often the respondent has to improve practices or is confronted with new exercises and things he has not learned.

\section{Table 7}

The percentage shares of respondents indicating that a specific requirement is frequently needed in their current job are shown in Table 8. The descriptive statistics show that jobs of well matched graduates (column 1) require key qualifications more often than jobs of overqualified graduates (column 2). For instance, 75 percent of well matched graduates have to solve and react to unexpected problems frequently while this is the case for merely 60 percent of overqualified graduates. Additionally, well-matched graduates 
more often have to convey complex issues, convince others, make difficult decisions independently, identify and close own knowledge gaps and perform many different tasks. The result that overqualified graduates hold jobs of lower complexity could indicate that they are less able than matched graduates. However, this cannot be proven with the data at hand. Columns 3 and 4 present the same statistics on key qualification requirements for workers who have completed a vocational training (medium-skilled). Jobs of well-matched, medium-skilled workers exhibit a higher frequency of key qualification requirements than jobs of overqualified, medium-skilled workers. These findings indicate that, for high-skilled and medium-skilled employees, overqualification goes along with a reduction in key qualification requirements of the job, so that well-matched employees hold the more complex jobs.

\section{Table 8}

Turning to the three further dimensions of job quality described in Table 8, results are similar. First, well-matched graduates more often have to work under time pressure or pressure to perform than overqualified graduates whereas working very fast is more often demanded in jobs of overqualified graduates (the same holds for medium-skilled employees). Second, well-matching jobs of graduates are less monotone than jobs of overqualified graduates or medium-skilled workers. For instance, 20 percent of well-matched graduates indicate that tasks are frequently repeating in every detail whereas this is the case for 47 percent of overqualified graduates. Finally, the descriptive statistics indicate that, for graduates and medium-skilled employees, well-matching jobs exhibit a higher extent of creativity requirements. The share of jobs frequently require that employees understand new exercises and improve practices are 20 percentage points higher for matched graduates than for overqualified graduates. For medium-skilled employees, these differences between matched and overqualification jobs amount to 10 percentage points.

Most of the overqualified graduates work in jobs requiring a vocational education. A second group holding jobs requiring a vocational education are medium-skilled workers matched with respect to their qualification. An interesting question is whether overqualified graduates hold higher quality jobs than those well-matched medium-skilled employees, although the educational requirements for the jobs are the same. To shed some light on this question, we compare job characteristics for overqualified graduates (column 2) and well-matched medium-skilled employees (column 3). The comparison indicates that overqualified graduates hold jobs with higher key qualification requirements than wellmatched medium-skilled employees, whereas the highest difference is found for the item convey complex issues. Differences are also found for the dimensions pressure, monotony and creativity. Graduates holding jobs requiring a vocational education more often have to face key qualification requirements and less often monotone tasks than well-matched employees holding a vocational education. For instance, only 17 percent of overqualified graduates indicate that job tasks are frequently prescribed in every detail, while this is 
the case for 25 percent of well-matched medium-skilled employees. However, if overqualified graduates and matched medium-skilled employees holding the same secondary school qualification ("Abitur") are compared, differences in job characteristics vanish.

Recent studies look at the combination of overqualification and skill mismatch in order to account for skill heterogeneity within qualification levels. We adopt this approach for examining differences in job characteristics according to type of mismatch. Skill mismatch is measured through the question of whether the worker feels unchallenged with respect to the professional knowledge and skill requirements in his job. For German graduates, we construct four categories of the match quality: a) neither overqualification nor skill mismatch, b) only skill mismatch, c) only overqualification, and d) both overqualification and skill mismatch. We show to what extent jobs held by graduates differ in the required level of complexity, pressure, monotony and creativity according to the match quality. Table 9 provides the percentage shares of graduates indicating that a certain requirement frequently occurs in his job.

\section{Table 9}

Solving unforeseeable problems is frequently required in 75 percent of the jobs held by graduates who are neither overqualified nor skill mismatched (column 1). For the group of only skill mismatched employees, the share is comparable and amounts to 76 percent (column 2). However, for overqualified graduates, we find a strong decline in the share of jobs that frequently require to solve unforeseeable problems. If graduates are affected by overqualification alone, the share amounts to 62 percent (column 3). For graduates being simultaneously overqualified and skill mismatched, the share decreases to 55 percent (column 4). We find that skill mismatch is less associated with a decrease in job complexity than overqualification. Except for the requirement to close own knowledge gaps, this holds for all items measuring this dimension of job characteristics. Nevertheless, the lowest job complexity is found for jobs of graduates being simultaneously overqualified and skill mismatched.

For the level of pressure a job exhibits, results are mixed. While mismatched graduates less often have to work under time pressure or reach the own capacity level, they have to work very fast more often than matched graduates. But, in general, jobs do not differ strongly in the level of pressure depending on the match quality. In contrast, the matching quality is strongly associated to the level of monotony a job exhibits. In only 6 percent of jobs held by matched graduates, tasks are prescribed in every detail, while this is the case for 25 percent of the jobs of graduates who are both overqualified and skill mismatched. Similarly, the share of jobs with repeating tasks increases from 19 percent for matched graduates to 63 percent for overqualification and skill mismatched graduates. Furthermore, we find that the creativity level a job exhibits is related to our measures of matching quality. For the items of this dimension, percentage shares of creative jobs are higher for matched graduates than for the three types of job mismatch. Again, the shares 
decrease more strongly due to overqualification than to skill mismatch and the lowest shares are found for graduates being overqualified and skill mismatched simultaneously. These findings highlight the differences in job characteristics according to the type of mismatch and shed some light on the consequences of qualification and skill mismatch on the job quality for German graduates.

\subsection{Selection into Qualification Mismatches}

In the previous sections, we have shown the consequences of job mismatches with respect to job quality and skill underutilization in specific competences ignoring a possible selection of graduates into overqualification or overskilling. If self-selection into mismatches is present, overqualified graduates could prefer having a low quality job or having more skills than required for the job. It also could be the case that the less able graduates are ending up in overqualification. For causal analyses, i.e. regarding wage effects of job mismatch, self-selection is a severe problem. This section shows some first results concerning possible self-selection for German graduates by employing HIS data. First, we show how the reasons to take a job differ between overqualified and matched graduates. Second, using detailed information about job satisfaction, we examine how overqualified and matched graduates differ in the preferences for specific job characteristics.

As argued in Section 2.2, there might be several reasons why workers could be willing to accept a job that is not optimal in terms of productivity. If one has the aim of improving the quality of the match between workers and jobs, it would be very informative to analyse to what extent mismatch is attributable to workers' choices and what the underlying reasons beyond these choices are. It might be the case that workers choose a mismatched position as a second best option because of specific market characteristics. We intend to investigate if the reasons for the choice of the job differ between overqualified and matched employees. Table 10 shows the percentage shares of workers indicating that a particular reason had a high or very high importance in the job choice for matched and overqualified graduates, respectively.

Table 10

Overqualified workers more often indicate that the lack of job alternatives and the avoidance of unemployment were important reasons for their job choice. For both items, the share of overqualified workers is about 17 percentage points higher than the share of matched workers. Roughly 50 percent of overqualified graduates indicate that these reasons were of (very) high importance. Firm reputation and interesting job tasks less often played a role in the employment decision for overqualified workers than for matched workers. This corresponds to the results in Section 4.4 and could indicate that jobs of overqualified graduates are less demanding or of lower "quality". In addition, this result could point to the importance of self-selection into overqualification if interesting tasks were of lower importance for overqualified graduates. 
The difference among overqualified and matched workers is small and not significant regarding the salary offer, the job security and the convenience of employment conditions. These results provide some evidence that workers on average do not choose jobs for which they are overqualified because of these job attributes. Overqualified workers indicate also less often that having good promotion prospects was an important reason for accepting their current job. This descriptive result appears to be in contrast to career mobility theory (Sicherman and Galor, 1990), which states that workers could choose to be overqualified for a short period if the probability of being promoted is higher in that position. However, a more rigorous analysis taking into account workers' heterogeneity in ability and training needs would be required for testing this theory.

The last two rows of Table 10 suggest that mobility constraints are important determinants for qualification mismatch. Indeed, overqualified workers more often report that the proximity to their native place and to their family or partner had a high importance for their job choice. As shown in Table 11, mobility and family constraints are only relevant for graduates of applied science universities and for females. The latter result is in line with the theory of differential overqualification developed by Frank (1978), who argues that gender differences in overqualification and in wages can partly be explained by the limited geographic mobility of married women with respect to men. Some evidence for Germany supporting this theory is found by Büchel and Battu (2003), who show that women in rural areas are less likely to commute over a long distance than men.

\section{Table 11}

In Section 4.4, we have shown that matched graduates hold more demanding jobs than overqualified graduates. This section additionally provides results about effects of qualification mismatches on job satisfaction. From an employee's perspective, the utility associated to a job is the relevant dimension for the definition of job mismatches (see Section 2.2). By employing very detailed information about job satisfaction, we provide some first insights into possible self-selection processes into qualification mismatch. In contrast to previous studies, we use not only information about overall job satisfaction.

Using HIS data, we examine to what extent graduates' satisfaction with respect to 15 specific job characteristics differ depending on the match quality. Table 12 provides the percentage shares of overqualified and matched graduates indicating that they are satisfied or very satisfied with the respective job characteristic. The share of matched graduates being (very) satisfied with the job content (83 percent) is significantly higher than the share of overqualified graduates ( 67 percent). The same holds for the satisfaction with respect to the professional position, training opportunities and the chance to bring in own ideas. These results are in line with the previous findings about the variation of job requirements depending on qualification mismatch and additionally indicate effects on the workers' job satisfaction. Overqualified graduates are less often (32 percent) satisfied with respect to their earnings than matched graduates (48 percent). Since various studies 
find significant wage penalties for overqualified employees, this result is not surprising. Nevertheless, satisfaction in this particular domain is likely to be strongly related to motivation and subsequently of high importance for productivity.

\section{Table 12}

Graduates have also been asked how satisfied they are with respect to the adequacy of the own qualification for the current job. A large share of matched graduates is (very) satisfied with the adequacy of own qualifications (67 percent). ${ }^{14}$ For overqualified graduates, the share drops to 33 percent. This decrease again could be explained by the fact that overqualification jobs are of lower quality, and thus graduates ending up in those jobs are less satisfied with the appropriateness of their qualification. However, the finding that a sizable proportion of overqualified graduates is satisfied in this respect could point to two different explanations. First, overqualified but satisfied graduates are those employees holding jobs which do not differ strongly from matched jobs. Second, the result could indicate that self-selection into qualification mismatch exists. This would be the case if overqualified but satisfied graduates preferred jobs of lower quality because they are less demanding for them.

In addition, a further finding could point to self-selection into qualification mismatch. The share of overqualified graduates being satisfied with the space for private life or the scope/length of working time is roughly 10 percentage points higher than for matched graduates. It is therefore possible that some graduates choose jobs they are overqualified for because they have higher preferences for leisure and a better work-life balance. Further research is needed to evaluate whether these results indicate self-selection or are only driven by differences in job characteristics.

\section{Conclusion}

In this study, we examine job-worker mismatch among German graduates both conceptually and empirically. We start with a conceptual underpinning of possible explanations of mismatch for different actors in the economy. The definition of mismatch differs according to the perspective that is taken into consideration. From the overall economy and the employer perspective, optimality of a job match hinges on productivity, while what matters for employees is the utility associated to a job. Nevertheless, the different definitions of mismatch are clearly associated with each other. For instance, being mismatched from an employee's perspective could reduce workers' motivation and effort leading to lower productivity, which is relevant from an overall economy perspective. Similarly, being mismatched from an overall economy perspective implies that, for a given worker, a job exists exhibiting a higher productivity level and thus higher earnings. Although earnings are

\footnotetext{
${ }^{14}$ Only 7 percent of matched graduates indicate being unsatisfied with the adequacy of own qualification and 25 percent indicate being indifferent.
} 
not the only determinant of the utility associated to a job, they are an important factor for the definition of mismatch from an employee's perspective.

The concepts of job mismatch employed in the empirical literature - qualification and skill mismatch - are relevant from each of the described perspectives. However, for employers, as well as for employees, mismatches according to these concepts could be an optimal choice. From an overall economy perspective, qualification or skill mismatches are sub-optimal if they imply productivity losses. Previous empirical literature has found strong negative effects of these types of mismatches on wages, which are employed as a proxy for productivity. Even if most coefficient estimates found are likely to be biased because of the failure to take into account unobserved ability (Leuven and Oosterbeek, 2011), the results suggest that qualification or skill mismatches imply productivity losses.

We employ these two concepts for an empirical analysis of job mismatch in Germany. The results indicate that a substantial share of German graduates are mismatched according to qualification or skills possessed. Although recent literature has unveiled several determinants of mismatch, the underlying mechanisms and causes have not been fully explored. We conclude from our review that, especially for Germany, further research focusing on unconsidered factors influencing the likelihood of mismatch could be fruitful. By presenting relevant datasets and variables, we provide an overview of such possible factors, e.g. job search intensity or study program characteristics.

Some German datasets provide information about workers' surplus or deficit in specific job-relevant competences. These self-ratings have been used only scarcely in the literature but could improve causal analyses concerning productivity effects of mismatch since they account for the multidimensionality of skills. We find that surpluses in competences are more strongly related to a direct skill mismatch measure than to overqualification. To the extent that skill surpluses are relevant for job productivity and concerns about the subjectivity of self-ratings of skill underutilization are not too high, a question on skill mismatch in employee surveys would be a better measure for job-worker mismatches from an overall economy perspective than a question on overqualification.

Finally, we underline the importance of considering possible self-selection processes into job mismatch. Our results concerning job choice and satisfaction with specific job characteristics suggest that some graduates may self-select into overqualified positions. In addition, we find that jobs of matched graduates exhibit higher complexity and creativity requirements while being less monotone than jobs held by mismatched graduates. Differences in graduates' preferences concerning these job characteristics could be a reason for self-selection. To what extent mismatched workers have different job preferences than matched workers remains an open question for further research. 


\section{Appendix}

Figure 1: Mismatch shares by experience groups
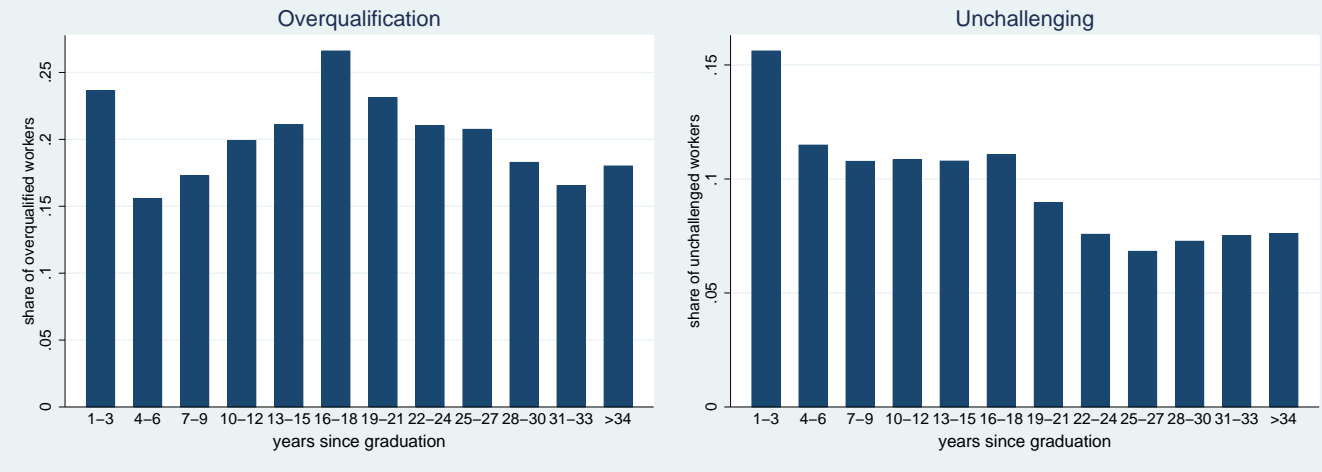

Skill underutilization

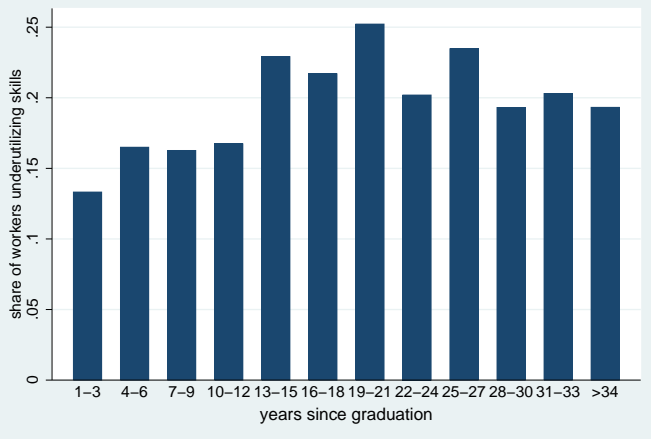

Source: BIBB/BAuA 2006. 


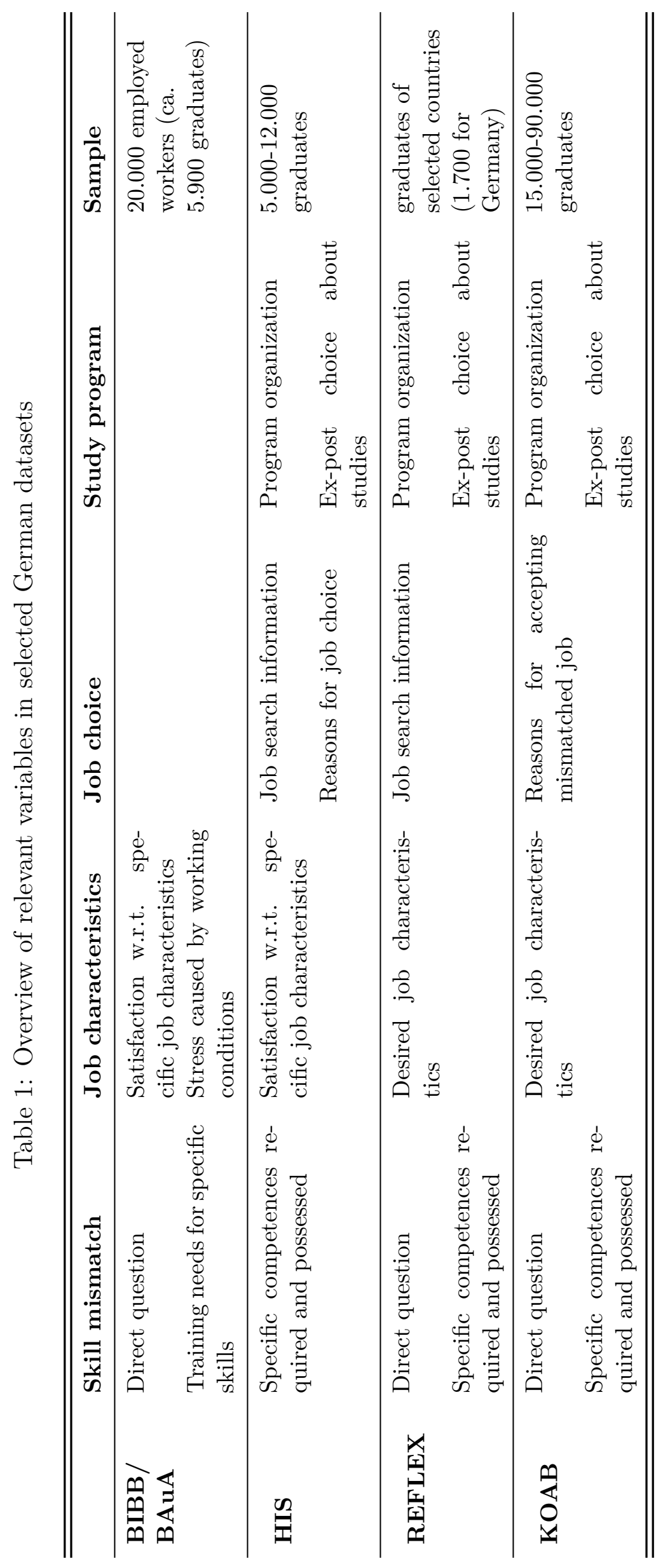


Table 2: Qualification and skill mismatch by country

\begin{tabular}{lcccccc}
\hline \hline & \multicolumn{2}{c}{ Qualification mismatch } & & \multicolumn{2}{c}{ Skill mismatch } & \multirow{2}{*}{ Obs. } \\
\cline { 2 - 3 } \cline { 5 - 6 } \cline { 5 - 6 } & Overqualified & Underqualified & & Overskilled & Underskilled & \\
\hline Spain & 30.8 & 7.0 & & 15.1 & 23.7 & 3.024 \\
Italy & 23.5 & 10.5 & & 11.1 & 23.3 & 2.036 \\
UK & 21.1 & 6.1 & & 14.0 & 25.3 & 1.268 \\
Belgium & 20.1 & 8.0 & & 8.4 & 26.6 & 1.043 \\
Germany & $\mathbf{1 6 . 4}$ & $\mathbf{6 . 9}$ & & $\mathbf{8 . 6}$ & $\mathbf{2 5 . 7}$ & $\mathbf{1 , 1 9 2}$ \\
Austria & 15.9 & 8.5 & & 8.9 & 28.7 & 1.261 \\
Netherlands & 15.6 & 5.4 & & 8.8 & 24.8 & 2.857 \\
Norway & 14.5 & 11.2 & & 4.4 & 28.5 & 1.868 \\
Finland & 10.1 & 4.6 & & 6.6 & 27.0 & 2.071 \\
\hline \hline
\end{tabular}

Note: Numbers in percentages. Source: REFLEX.

Table 3: Overqualification by field of study, type of university and gender

\begin{tabular}{|c|c|c|c|c|c|c|}
\hline & \multicolumn{2}{|c|}{ University type } & \multicolumn{2}{|c|}{ Gender } & \multirow{2}{*}{ Total } & \multirow{2}{*}{ Obs. } \\
\hline & University & $\begin{array}{c}\text { University of } \\
\text { applied sciences }\end{array}$ & Male & Female & & \\
\hline Medicine and health & 1.0 & $\mathrm{~m}^{\mathrm{a}}$ & 0.0 & 1.5 & 1.0 & 210 \\
\hline Teaching & 2.4 & $\mathrm{~m}^{\mathrm{a}}$ & 1.8 & 2.6 & 2.4 & 496 \\
\hline Law & 9.5 & $\mathrm{~m}^{\mathrm{a}}$ & 10.2 & 8.8 & 9.5 & 127 \\
\hline $\begin{array}{l}\text { Mathematics, natural sci- } \\
\text { ences, computing }\end{array}$ & 7.8 & 18.2 & 8.1 & 11.2 & 9.6 & 636 \\
\hline $\begin{array}{l}\text { Engineering and construc- } \\
\text { tion }\end{array}$ & 11.3 & 18.8 & 13.3 & 19.6 & 16.2 & 1,220 \\
\hline $\begin{array}{l}\text { Social and behavioural sci- } \\
\text { ences }\end{array}$ & 29.5 & 21.6 & 24.6 & 26.9 & 26.4 & 539 \\
\hline Humanities and Arts & 26.3 & 39.4 & 20.0 & 31.5 & 27.6 & 326 \\
\hline Business and economics & 19.8 & 39.3 & 25.8 & 30.5 & 28.0 & 411 \\
\hline Other subjects & 21.3 & 32.3 & 22.0 & 25.6 & 24.7 & 215 \\
\hline Total & 13.1 & 22.9 & 14.1 & 18.1 & 16.4 & 4,180 \\
\hline
\end{tabular}

Note: Numbers in percentages. ${ }^{a}$ Values are missing since universities of applied sciences do not offer degrees in this field of study. Source: HIS-Graduate Panel 2001 
Table 4: Qualification and skill mismatch by field of study

\begin{tabular}{|c|c|c|c|c|}
\hline & \multirow{2}{*}{$\frac{\text { Qualification mismatch }}{\text { Overqualified }}$} & \multicolumn{2}{|c|}{ Skill mismatch } & \multirow{2}{*}{ Obs. } \\
\hline & & Unchallenged & Skill underutilization & \\
\hline Medicine and health & 5.8 & 5.8 & 4.6 & 154 \\
\hline Teaching & 8.7 & 7.1 & 22.2 & 909 \\
\hline Law & 15.1 & 11.1 & 7.9 & 127 \\
\hline $\begin{array}{l}\text { Mathematics, natural sci- } \\
\text { ences, computing }\end{array}$ & 16.7 & 8.9 & 24.7 & 435 \\
\hline $\begin{array}{l}\text { Engineering and construc- } \\
\text { tion }\end{array}$ & 22.0 & 9.3 & 21.4 & 996 \\
\hline $\begin{array}{l}\text { Social and behavioural sci- } \\
\text { ences }\end{array}$ & 23.7 & 10.0 & 14.1 & 520 \\
\hline Humanities and arts & 23.3 & 16.2 & 22.8 & 236 \\
\hline Business and economics & 29.7 & 10.5 & 15.1 & 591 \\
\hline Other subjects & 30.4 & 14.9 & 17.4 & 487 \\
\hline Total & 20.2 & 10.0 & 18.9 & 4,455 \\
\hline
\end{tabular}

Note: Numbers in percentages. Source: BIBB/BAuA 2006

Table 5: Mismatch in specific competences

\begin{tabular}{lccc}
\hline \hline & \multicolumn{2}{c}{ Level of graduate's competence } \\
\cline { 2 - 4 } & Surplus & Appropriate & Deficit \\
\hline Mastery of own field & 10.2 & 82.8 & 7.1 \\
Knowledge of other fields & 19.3 & 73.7 & 7.1 \\
Analytical thinking & 15.1 & 82.3 & 2.6 \\
Rapidly acquire new knowledge & 15.1 & 80.8 & 4.1 \\
Negotiate effectively & 18.6 & 69.8 & 11.6 \\
Perform well under pressure & 9.3 & 82.0 & 8.7 \\
Alertness to new opportunities & 17.3 & 76.2 & 6.6 \\
Coordinate activities & 13.9 & 80.8 & 5.2 \\
Use time effectively & 9.5 & 74.9 & 15.7 \\
Work productively with others & 14.4 & 82.4 & 3.2 \\
Mobilize the capacities of others & 18.1 & 72.7 & 9.3 \\
Make meaning clear to others & 15.2 & 76.5 & 8.3 \\
Assert authority & 17.3 & 69.5 & 13.1 \\
Use computers and the internet & 18.7 & 77.9 & 3.4 \\
Come up with new ideas and solutions & 17.0 & 77.5 & 5.5 \\
Willingness to question own and others' ideas & 24.0 & 71.7 & 4.3 \\
Present products, ideas or report to an audience & 19.5 & 70.6 & 10.0 \\
Write reports or documents & 17.3 & 76.7 & 6.1 \\
Write/speak in foreign language & 30.6 & 59.8 & 9.5 \\
\hline \hline
\end{tabular}

Note: Numbers in percentages. Source: REFLEX. 
Table 6: Surplus of specific competences by qualification and skill match

\begin{tabular}{|c|c|c|c|c|c|c|}
\hline & \multicolumn{3}{|c|}{ Qualification match } & \multicolumn{3}{|c|}{ Skill match } \\
\hline & Matched & Overqual. & Diff. & Matched & Oversk. & Diff. \\
\hline Mastery of own field & 8.6 & 18.1 & $-9.5^{* * *}(-3.91)$ & 8.4 & 30.0 & $-21.6^{* * *}(-6.61)$ \\
\hline Knowledge of other fields & 17.4 & 28.6 & $-11.2^{* * *}(-3.50)$ & 18.6 & 26.7 & $-8.1 \quad(-1.86)$ \\
\hline Analyitcal thinking & 13.3 & 24.2 & $-10.8^{* * *}(-3.75)$ & 13.8 & 30.0 & $-16.2^{* * *}(-4.14)$ \\
\hline Rapidly acquire new knowledge & 14.2 & 19.2 & $-5 \quad(-1.73)$ & 13.8 & 28.9 & $-15.1^{* * *}(-3.86)$ \\
\hline Negotiate effectively & 18.2 & 20.9 & $(-0.86)$ & 17.9 & 26.7 & $-8.8^{*} \quad(-2.05)$ \\
\hline Perform well under pressure & 9.5 & 8.2 & $(-0.52)$ & 8.8 & 14.4 & $-5.6 \quad(-1.77)$ \\
\hline Alertness to new opportunities & 16.0 & 23.6 & $-7.7^{*}(-2.50)$ & 16.5 & 25.6 & $-9.1^{*}(-2.18)$ \\
\hline Coordinate activities & 12.3 & 22.0 & $-9.6 * * *(-3.44)$ & 13.6 & 17.8 & $-4.2 \quad(-1.10)$ \\
\hline Use time effectively & 9.6 & 8.8 & $0.8 \quad(-0.33)$ & 8.6 & 18.9 & $-10.3^{* *}(-3.21)$ \\
\hline Work productively with others & 14.9 & 12.1 & $(-0.97)$ & 13.4 & 25.6 & $-12.2^{* *}(-3.16)$ \\
\hline Mobilize the capacities of others & 17.3 & 22.0 & $(-1.50)$ & 16.8 & 32.2 & $-15.4^{* * *}(-3.66)$ \\
\hline Make meaning clear to others & 14.8 & 17.6 & $(-0.97)$ & 13.8 & 31.1 & $-17.3^{* * *}(-4.41)$ \\
\hline Assert authority & 16.5 & 21.4 & $(-1.60)$ & 16.2 & 30.0 & $-13.8^{* * *(-3.33)}$ \\
\hline Use computers and the internet & 18.5 & 19.8 & $-1.3 \quad(-0.40)$ & 17.6 & 31.1 & $-13.5^{* *}(-3.16)$ \\
\hline Come up with new ideas & 14.6 & 28.6 & $-13.9^{* * *}(-4.61)$ & 14.8 & 41.1 & $-26.3^{* * *}(-6.48)$ \\
\hline Willingness to question ideas & 22.1 & 33.5 & $-11.4^{* *}(-3.29)$ & 22.4 & 42.2 & $-19.8^{* * *(-4.25)}$ \\
\hline Present products, ideas & 17.7 & 28.0 & $-10.3^{* *}(-3.21)$ & 17.8 & 37.8 & $-20 * * *(-4.63)$ \\
\hline Write reports or documents & 15.3 & 26.9 & $-11.6^{* * *}(-3.81)$ & 15.5 & 36.7 & $-21.2^{* * *}(-5.15)$ \\
\hline Write/speak in foreign language & 29.5 & 36.3 & $(-1.80)$ & 29.2 & 46.7 & $-17.5^{* * *}(-3.46)$ \\
\hline Obs. & 908 & 182 & & 1000 & 90 & \\
\hline
\end{tabular}

Note: Numbers in percentages; $t$ statistics in parentheses; ${ }^{*} p<0.05,{ }^{* *} p<0.01,{ }^{* * *} p<0.001$. Source: REFLEX.

Table 7: Dimensions of job characteristics

\begin{tabular}{|c|c|c|}
\hline $\begin{array}{l}\text { Dimension of } \\
\text { job characteristics }\end{array}$ & Item & Description \\
\hline Complexity & $\begin{array}{l}\text { solve problems } \\
\text { convey complex issues } \\
\text { convince others } \\
\text { difficult decisions } \\
\text { own knowledge gaps } \\
\text { different tasks }\end{array}$ & $\begin{array}{l}\text { solve or react to unforeseeable problems } \\
\text { convey complex issues comprehensibly } \\
\text { convince others and negotiate compromises } \\
\text { independently make difficult decisions } \\
\text { identify and close own knowledge gaps } \\
\text { perform many different tasks }\end{array}$ \\
\hline Pressure & $\begin{array}{l}\text { time pressure } \\
\text { capacity limit } \\
\text { work very fast }\end{array}$ & $\begin{array}{l}\text { time pressure or pressure to perform } \\
\text { reach your own capacity limit } \\
\text { work very fast }\end{array}$ \\
\hline Monotony & $\begin{array}{l}\text { prescribed tasks } \\
\text { repeating tasks }\end{array}$ & $\begin{array}{l}\text { job tasks prescribed in every detail } \\
\text { same task repeats in every detail }\end{array}$ \\
\hline Creativity & $\begin{array}{l}\text { new exercises } \\
\text { improve practices } \\
\text { things not learned }\end{array}$ & $\begin{array}{l}\text { new exercises occur that you have to understand } \\
\text { improve practices or try something new } \\
\text { things are demanded that you have not learned }\end{array}$ \\
\hline
\end{tabular}

Source: BIBB/BAuA 2006 
Table 8: Job characteristics by qualification match

\begin{tabular}{|c|c|c|c|c|}
\hline & \multicolumn{2}{|c|}{ Graduates } & \multicolumn{2}{|c|}{ Medium skilled } \\
\hline & Matched & Overqualified & Matched & Overqualified \\
\hline \multicolumn{5}{|l|}{ Complexity } \\
\hline solve problems & 75.0 & 59.9 & 54.2 & 39.8 \\
\hline convey complex issues & 74.8 & 47.4 & 36.4 & 22.8 \\
\hline convince others & 66.4 & 43.8 & 37.0 & 23.7 \\
\hline difficult decisions & 61.6 & 45.9 & 39.6 & 28.2 \\
\hline close knowledge gaps & 46.5 & 30.1 & 27.9 & 19.7 \\
\hline different tasks & 84.3 & 73.4 & 75.3 & 58.8 \\
\hline \multicolumn{5}{|l|}{ Pressure } \\
\hline time pressure & 63.8 & 54.8 & 56.5 & 49.0 \\
\hline capacity limit & 16.0 & 13.4 & 17.0 & 17.2 \\
\hline work very fast & 35.9 & 42.9 & 46.5 & 48.1 \\
\hline \multicolumn{5}{|l|}{ Monotony } \\
\hline prescribed tasks & 6.2 & 16.6 & 25.2 & 32.8 \\
\hline repeating tasks & 20.1 & 46.7 & 54.5 & 68.1 \\
\hline \multicolumn{5}{|l|}{ Creativity } \\
\hline new exercises & 63.3 & 42.4 & 38.7 & 26.4 \\
\hline improve practices & 49.5 & 29.6 & 26.2 & 16.6 \\
\hline things not learned & 12.4 & 8.2 & 8.5 & 8.4 \\
\hline
\end{tabular}

Note: Numbers in percentages. Source: BIBB/BAuA 2006

Table 9: Job characteristics by qualification and skill match

\begin{tabular}{|c|c|c|c|c|}
\hline & Matched & $\begin{array}{c}\text { Only } \\
\text { skill mismatched }\end{array}$ & $\begin{array}{c}\text { Only } \\
\text { overqualified }\end{array}$ & $\begin{array}{l}\text { Overqualified and } \\
\text { skill mismatched }\end{array}$ \\
\hline \multicolumn{5}{|l|}{ Complexity } \\
\hline solve problems & 74.9 & 75.8 & 61.6 & 54.8 \\
\hline convey complex issues & 75.1 & 71.0 & 50.4 & 38.0 \\
\hline convince others & 66.4 & 65.4 & 45.1 & 39.9 \\
\hline difficult decisions & 61.6 & 60.2 & 49.5 & 34.6 \\
\hline close knowledge gaps & 47.4 & 32.9 & 33.2 & 20.2 \\
\hline different tasks & 84.6 & 78.8 & 75.0 & 68.3 \\
\hline \multicolumn{5}{|l|}{ Pressure } \\
\hline time pressure & 64.2 & 58.4 & 55.6 & 52.4 \\
\hline capacity limit & 16.0 & 16.5 & 13.4 & 13.5 \\
\hline work very fast & 36.0 & 35.8 & 42.1 & 45.7 \\
\hline \multicolumn{5}{|l|}{ Monotony } \\
\hline prescribed tasks & 5.8 & 12.1 & 14.1 & 24.6 \\
\hline repeating tasks & 19.4 & 31.6 & 41.6 & 63.0 \\
\hline \multicolumn{5}{|l|}{ Creativity } \\
\hline new exercises & 64.1 & 51.5 & 46.6 & 28.9 \\
\hline improve practices & 50.1 & 41.6 & 31.6 & 23.1 \\
\hline things not learned & 12.4 & 11.7 & 8.8 & 6.3 \\
\hline
\end{tabular}

Note: Numbers in percentages. Source: BIBB/BAuA 2006 
Table 10: Reasons for job choice by qualification match

\begin{tabular}{lcccc}
\hline \hline & Matched & Overqualified & \multicolumn{2}{c}{ Diff. } \\
\hline Lack of job alternatives & 28.2 & 45.7 & $-17.5^{* * *}$ & $(-8.94)$ \\
Avoid unemployment & 37.8 & 54.9 & $-17.1^{* * *}$ & $(-8.25)$ \\
Firm reputation & 44.4 & 36.9 & $7.5^{* * *}$ & $(3.54)$ \\
Interesting tasks & 85.2 & 77.1 & $8.1^{* * *}$ & $(5.23)$ \\
Salary offer & 34.7 & 34.3 & 0.5 & $(0.23)$ \\
Job security & 49.9 & 50.2 & -0.4 & $(-0.17)$ \\
Convenient employment conditions & 54.5 & 56.6 & -2.1 & $(-0.99)$ \\
Good promotion prospects & 31.8 & 27.2 & $4.6^{*}$ & $(2.34)$ \\
Proximity to native place & 41.5 & 50.1 & $-8.6^{* * *}$ & $(-4.08)$ \\
Partner/family related reasons & 31.8 & 35.8 & $-4.0^{*}$ & $(-1.99)$ \\
\hline Obs. & 3340 & 651 & & \\
\hline \hline
\end{tabular}

Note: Numbers in percentages; $t$ statistics in parentheses;

${ }^{*} p<0.05,{ }^{* *} p<0.01,{ }^{* * *} p<0.001$. Source: HIS-Graduate Panel 2001

Table 11: Importance of partner/family related reasons for job decision

\begin{tabular}{lcccc}
\hline \hline & Matched & Overqualified & \multicolumn{2}{c}{ Diff. } \\
\hline Female & 33.7 & 39.4 & $-5.7^{*}$ & $(-2.16)$ \\
Male & 26.5 & 29.6 & -3.2 & $(-1.01)$ \\
\hline University of applied sciences & 27.8 & 38.5 & $-10.7^{* * *}$ & $(-3.58)$ \\
University & 31.6 & 33.5 & -1.9 & $(-0.69)$ \\
\hline \hline
\end{tabular}

Note: Numbers in percentages; $t$ statistics in parentheses;

${ }^{*} p<0.05,{ }^{* *} p<0.01,{ }^{* * *} p<0.001$. Source: HIS-Graduate Panel 2001 
Table 12: Satisfaction with job characteristics by qualification match

\begin{tabular}{lcccc}
\hline \hline & Matched & Overqualified & \multicolumn{2}{c}{ Diff. } \\
\hline Job content & 83.1 & 67.4 & $15.7^{* * *}$ & $(9.51)$ \\
Professional position & 68.8 & 47.4 & $21.4^{* * *}$ & $(10.80)$ \\
Training opportunities & 48.8 & 37.0 & $11.8^{* * *}$ & $(5.63)$ \\
Chance to bring in own ideas & 69.6 & 57.9 & $11.6^{* * *}$ & $(5.93)$ \\
Earnings & 48.4 & 31.9 & $16.6^{* * *}$ & $(7.95)$ \\
Promotion prospects & 32.4 & 24.7 & $7.7^{* * *}$ & $(3.93)$ \\
Working atmosphere & 76.1 & 66.8 & $9.3^{* * *}$ & $(5.10)$ \\
Job security & 63.0 & 58.7 & $4.3^{*}$ & $(2.10)$ \\
Adequacy of qualification & 66.7 & 33.2 & $33.6^{* * *}$ & $(16.90)$ \\
Working conditions & 59.6 & 56.9 & 2.7 & $(1.31)$ \\
Technical facilities & 62.0 & 60.4 & 1.5 & $(0.75)$ \\
Family-friendliness & 41.2 & 40.6 & 0.7 & $(0.31)$ \\
Organization of working time & 57.0 & 55.0 & 2.0 & $(0.96)$ \\
Space for private life & 43.4 & 52.9 & $-9.5^{* * *}$ & $(-4.54)$ \\
Scope/length of working time & 41.7 & 51.1 & $-9.4^{* * *}$ & $(-4.51)$ \\
\hline Obs. & 3404 & 675 & & \\
\hline \hline
\end{tabular}

Note: Numbers in percentages; $t$ statistics in parentheses;

${ }^{*} p<0.05,{ }^{* *} p<0.01,{ }^{* * *} p<0.001$. Source: HIS-Graduate Panel 2001 


\section{References}

Acemoglu, D. and Autor, D. (2011). Skills, Tasks and Technologies: Implications for Employment and Earnings. In Ashenfelter, O. and Card, D., editors, Handbook of Labor Economics, volume 4, pages 1043-1171. Elsevier.

Albrecht, J. and Vroman, S. (2002). A Matching Model with Endogenous Skill Requirements. International Economic Review, 43(1):283-305.

Allen, J. and van der Velden, R. (2001). Educational Mismatches Versus Skill Mismatches: Effects on Wages, Job Satisfaction, and On-The-Job Search. Oxford Economic Papers, 53(3):434-452.

Bauer, T. (2002). Educational Mismatch and Wages: A Panel Analysis. Economics of Education Review, 21(3):221-229.

Bowen, D., Ledford Jr, G., and Nathan, B. (1991). Hiring for the Organization, Not the Job. The Executive, pages 35-51.

Bowlus, A. (1995). Matching Workers and Jobs: Cyclical Fluctuations in Match Quality. Journal of Labor Economics, 13(2):335-350.

Brown, C. (1980). Equalizing Differences in the Labor Market. The Quarterly Journal of Economics, 94(1):113-134.

Brunello, G., Garibaldi, P., and Wasmer, E. (2007). Education and Training in Europe. OUP Catalogue.

Büchel, F. (1996). Der Hohe Anteil an Unterwertig Beschäftigten bei Jüngeren Akademikern: Karrierezeitpunkt-oder Strukturwandel-Effekt. Mitteilungen aus der Arbeitsmarktund Berufsforschung, 29(2):279-294.

Büchel, F. (2002). The Effects of Overeducation on Productivity in Germany-the Firms' Viewpoint. Economics of Education Review, 21(3):263-275.

Büchel, F. and Battu, H. (2003). The Theory of Differential Overqualification: Does It Work? Scottish Journal of Political Economy, 50(1):1-16.

Cedefop (2010). The Skill Matching Challenge - Analysing Skill Mismatch and Policy Implications. Technical report, Cedefop.

Cedefop (2012). Skill Mismatch - The Role of the Enterprise. Research Paper 21, Cedefop.

Chevalier, A. (2003). Measuring Over-Education. Economica, 70(279):509-531.

Clark, A. (2001). What Really Matters in a Job? Hedonic Measurement Using Quit Data. Labour Economics, 8(2):223-242. 
Clark, A., Frijters, P., and Shields, M. (2008). Relative Income, Happiness, and Utility: An Explanation for the Easterlin Paradox and Other Puzzles. Journal of Economic Literature, 46(1):95-144.

Clark, A. and Oswald, A. (1996). Satisfaction and Comparison Income. Journal of Public Economics, 61(3):359-381.

Converse, P., Oswald, F., Gillespie, M., Field, K., and Bizot, E. (2004). Matching Individuals to Occupations Using Abilities and the O* NET: Issues and an Application in Career Guidance. Personnel Psychology, 57(2):451-487.

Desjardins, R. and Rubenson, K. (2011). An Analysis of Skill Mismatch Using Direct Measures of Skills. OECD Education Working Papers.

Destatis (2011). Bildungsfinanzbericht 2011. Technical report, Statistisches Bundesamt.

Di Pietro, G. and Cutillo, A. (2006). University Quality and Labour Market Outcomes in Italy. Labour, 20(1):37-62.

Dolado, J., Jansen, M., and Jimeno, J. (2009). On-the-Job Search in a Matching Model with Heterogeneous Jobs and Workers. The Economic Journal, 119(534):200-228.

Duncan, G. and Hoffman, S. (1982). The Incidence and Wage Effects of Overeducation. Economics of Education Review, 1(1):75-86.

Fehse, S. and Kerst, C. (2007). Arbeiten Unter Wert? Vertikal und Horizontal Inadäquate Beschäftigung von Hochschulabsolventen der Abschlussjahrgänge 1997 und 2001. Beiträge zur Hochschulforschung, 29(1):72-98.

Ferreira, P. and Taylor, M. (2011). Measuring Match Quality Using Subjective Data. Economics Letters, 113(3):304-306.

Frank, R. (1978). Why Women Earn Less: The Theory and Estimation of Differential Overqualification. The American Economic Review, 68(3):360-373.

Freeman, R. B. (1976). The Overeducated American. Academic Press.

Frenette, M. (2004). The Overqualified Canadian Graduate: The Role of the Academic Program in the Incidence, Persistence, and Economic Returns to Overqualification. Economics of Education Review, 23(1):29-45.

Green, F. and McIntosh, S. (2007). Is There a Genuine Under-Utilization of Skills Amongst the Over-Qualified? Applied Economics, 39(4):427-439.

Green, F. and Zhu, Y. (2010). Overqualification, Job Dissatisfaction, and Increasing Dispersion in the Returns to Graduate Education. Oxford Economic Papers, 62(4):740763. 
Groot, W. and Maassen van den Brink, H. (2000). Overeducation in the Labor Market: A Meta-Analysis. Economics of Education Review, 19(2):149-158.

Hall, A. (2009). Die BIBB/BAuA-Erwerbstätigenbefragung 2006 - Methodik und Frageprogramm im Vergleich zur BIBB/ IAB-Erhebung 1998. Technical report, Bundesinstitut für Berufsbildung (BIBB).

Hartog, J. (2000). Over-education and Earnings: Where Are We, Where Should We Go? Economics of Education Review, 19(2):131-147.

Hersch, J. (1991). Education Match and Job Match. The Review of Economics and Statistics, pages 140-144.

Hunt, G. and Mueller, R. (2004). North American Migration: Returns to Skill, Border Effects, and Mobility Costs. Review of Economics and Statistics, 86(4):988-1007.

Hwang, H., Mortensen, D., and Reed, W. (1998). Hedonic Wages and Labor Market Search. Journal of Labor Economics, 16(4):815-47.

Hwang, H., Reed, W., and Hubbard, C. (1992). Compensating Wage Differentials and Unobserved Productivity. Journal of Political Economy, 100(4):835-858.

Jansen, K. and Kristof-Brown, A. (2006). Toward a Multidimensional Theory of PersonEnvironment Fit. Journal of Managerial Issues, pages 193-212.

Jovanovic, B. (1979). Job Matching and the Theory of Turnover. The Journal of Political Economy, 87(5):972-990.

Korpi, T. and Tåhlin, M. (2009). Educational Mismatch, Wages, and Wage Growth: Overeducation in Sweden, 1974-2000. Labour Economics, 16(2):183-193.

Kristof-Brown, A., Zimmerman, R., and Johnson, E. (2005). Consequences of Individuals' Fit at Work: A Meta-Analysis of Person-Job, Person-Organization, Person-Group, and Person-Supervisor Fit. Personnel Psychology, 58(2):281-342.

Lazear, E. (1998). Hiring Risky Workers. In Ohashi, I. and Tachibanaki, T., editors, Internal Labour Market, Incentives and Employment, chapter Employment Policy. Palgrave Macmillan.

Leuven, E. and Oosterbeek, H. (2011). Overeducation and Mismatch in the Labor Market. In E., H. A., Machin, S., and Woessmann, L., editors, Handbook of the Economics of Education, volume 4, pages 283-326. Elsevier.

McGoldrick, K. and Robst, J. (1996). Gender Differences in Overeducation: A Test of the Theory of Differential Overqualification. The American Economic Review, 86(2):280284. 
McGuinness, S. (2003). University Quality and Labour Market Outcomes. Applied Economics, 35(18):1943-1955.

Mortensen, D. and Pissarides, C. (1999). New Developments in Models of Search in the Labor Market. In Ashenfelter, O. and Card, D., editors, Handbook of Labor Economics, volume 3, pages 2567-2627. Elsevier.

Muchinsky, P. and Monahan, C. (1987). What is Person-Environment Congruence? Supplementary Versus Complementary Models of Fit. Journal of Vocational Behavior, 31(3):268-277.

OECD (2012). Education at a Glance 2012: OECD Indicators. Technical report, OECD Publishing.

Oyer, P. and Schaefer, S. (2011). Personnel Economics: Hiring and Incentives. In Ashenfelter, O. and Card, D., editors, Handbook of Labor Economics, volume 4, pages 17691823. Elsevier.

Pellizzari, M. (2011). Employers' Search and the Efficiency of Matching. British Journal of Industrial Relations, 49(1):25-53.

Plicht, H., Schober, K., and Schreyer, F. (1994). Zur Ausbildungsadäquanz der Beschäftigung von Hochschulabsolventinnen und-absolventen. MittAB, 27(3):177-204.

Quintini, G. (2011). Right for the Job: Over-Qualified or Under-Skilled? Working paper, OECD Social, Employment and Migration Working Papers.

Riphahn, R. T., Eschelbach, M., Heineck, G., and Müller, S. (2010). Kosten und Nutzen der Ausbildung an Tertärbildungsinstitutionen im Vergleich. Perspektiven der Wirtschaftspolitik, 11(2):103-131.

Robst, J. (1995). College Quality and Overeducation. Economics of Education Review, $14(3): 221-228$.

Rumberger, R. (1987). The Impact of Surplus Schooling on Productivity and Earnings. Journal of Human Resources, pages 24-50.

Sattinger, M. (1993). Assignment Models of the Distribution of Earnings. Journal of Economic Literature, 31(2):831-880.

Sattinger, M. (2012). Assignment Models and Quantitative Mismatches. Prepared for the Expert Workshop "Skill Mismatch and Firm Dynamics: Integrating Skills with the World of Work," April 27, London.

Searle, R. (2009). Recruitment and Selection. In Collings, D. G. and Wood, G., editors, Human Resource Management: A Critical Approach, chapter The Practice of HRM, pages 151-168. Taylor \& Francis. 
Sicherman, N. and Galor, O. (1990). A Theory of Career Mobility. Journal of Political Economy, 98(1):169-92.

Sloane, P. (2003). Much Ado about Nothing? What Does the Overeducation Literature Really Tell Us. In Büchel, F., de Grip, A., and Mertens, A., editors, Overeducation in Europe: Current Issues in Theory and Policy, page 11-48.

Smith, J. and Welch, F. (1978). The Overeducated American?: A Review Article. Rand.

Spitz-Oener, A. (2006). Technical Change, Job Tasks, and Rising Educational Demands: Looking Outside the Wage Structure. Journal of Labor Economics, 24(2):235-270.

Teulings, C. and Gautier, P. (2004). The Right Man for the Job. Review of Economic Studies, 71(2):553-580.

Tsai, Y. (2010). Returns to Overeducation: A Longitudinal Analysis of the US Labor Market. Economics of Education Review, 29(4):606-617.

Tsang, M. (1987). The Impact of Underutilization of Education on Productivity: A Case Study of the US Bell Companies. Economics of Education Review, 6(3):239-254.

Tsang, M., Rumberger, R., and Levin, H. (1991). The Impact of Surplus Schooling on Worker Productivity. Industrial Relations: A Journal of Economy and Society, 30(2):209-228.

Verdugo, R. and Verdugo, N. (1989). The Impact of Surplus Schooling on Earnings: Some Additional Findings. Journal of Human Resources, pages 629-643.

Verhaest, D. and Omey, E. (2006). The Impact of Overeducation and its Measurement. Social Indicators Research, 77(3):419-448.

Verhaest, D. and van der Velden, R. (2012). Cross-Country Differences in Graduate Overeducation. European Sociological Review. 